\title{
Role of Probiotics in Pancreatic Cancer Prevention: The Prospects and Challenges
}

\author{
Barkha Singhal*, Ankita Mukherjee, Shubham Srivastav \\ School of Biotechnology, Gauatm Buddha University, Greater Noida, India \\ Email: ^barkha@gbu.ac.in, ‘gupta.barkha@gmail.com, ankitamukharji123@gmail.com,shubham_sri1@yahoo.com
}

How to cite this paper: Singhal, B., Mukherjee, A. and Srivastav, S. (2016) Role of Probiotics in Pancreatic Cancer Prevention: The Prospects and Challenges. Advances in Bioscience and Biotechnology, 7, 468-500. http://dx.doi.org/10.4236/abb.2016.711045

Received: October 17, 2016

Accepted: November 27, 2016

Published: November 30, 2016

Copyright $\odot 2016$ by authors and Scientific Research Publishing Inc. This work is licensed under the Creative Commons Attribution International License (CC BY 4.0).

http://creativecommons.org/licenses/by/4.0/ (c) (i)

Open Access

\begin{abstract}
Pancreatic cancer is expressed as a disorder of chaos that leads to impairment in biochemical and metabolic physiology of pancreas. It is considered as the most intractable and fatal among all gastrointestinal (GI) cancers. The early occurrence of metastatic spread and the development of intrinsic and acquired resistance during drug treatment limit its prognosis at the right time. The universalized treatment involves surgical resection in which only a minority $(<20 \%)$ of patients qualify due to advanced stage of disease at the time of diagnosis. Despite the rigorous technological developments in understanding the molecular mechanism of pancreatic cancer, no significant advances in efficacy of chemotherapeutic treatment have been arisen till date and still present challenges to overcome. That leads to the scientists to undergo exhaustive research to find an alternative treatment and increasing focus have been given on the studies of symbiotic relationships between microbiota and host which confers benefits to the host in many key aspects of life and form a synergistic harmony so called "super-organism". The perturbations in the regulatory circuits of the host that control homeostasis, or alterations of the microbiome, through environmental changes (infection, diet or lifestyle), may disturb this symbiotic relationship and favors carcinogenesis in the pancreas. Research studies speculating convincing evidence that, among the gut microbiota, probiotics have demonstrated their potential role in the prevention of all stages of cancer development, but the critical question has been arisen that Can probiotics be used as preventive targets for pancreatic cancer? Thus, the efforts have been directed towards to summarize the prospective and challenging role of probiotics as preventive approach for pancreatic cancer. Though prospects of probiotics in prevention of pancreatic cancer are being great challenge among research community therefore, more rigorous and well-designed in vitro, animal and clinical studies are required for worthy manifestations.
\end{abstract}

\section{Keywords}

Gut Microbiota, Immunomodulation, Lifestyle Diseases, Probiotics, 
Pancreatic Cancer, Pancreatitis

\section{Introduction}

The human gut, the largest microbial reservoir in the body, harbors about $10^{13-14} \mathrm{mi}-$ croorganisms [1]. These microorganisms are collectively referred to as microbiota, while their collective genomes constitute known as the microbiome [2] [3]. Most of these gut microorganisms reside in the large intestine (colon), which contains an estimated $10^{11-12}$ bacterial concentrations per gram of content [4]. There is a mutual interaction between intestinal cells and microorganisms present in the gastrointestinal tract [5]. Commensal microorganisms in the gastrointestinal tract exert a significant effect on host biochemistry such as oxidation-reduction potential of luminal contents, enzymatic activity of intestinal contents, host physiology, short chain fatty acid production in the lumen, synthesis of vitamins and prevention against colonization by pathogen, immunomodulation and modification of host-synthesized molecules [6] [7]. There is an established association between existing microbiota and intestinal function for maintaining of homeostasis, building of balanced immunity. Any microbial alterations may lead to dysbiosis, a contributing factor for the onset and progression of several chronic diseases including cancer [8]. Among cancer, pancreatic cancer is the fourth leading cause of cancer mortality with poor prognosis and overall 5-year survival is only less than 5\%. Even patients undergone complete resection, chemotherapy and radiation have a 5-year survival of only 20\% [9] [10]. Research studies revealed that intestinal barrier dysfunction and subsequent bacterial translocation from the intestinal tract to the bloodstream and necrotic tissues plays a critical role in the infection of pancreatic tissues. Interestingly, the pancreas does not have an identified microbiome however; it can be deeply affected by dysbiosis in the gut. Bacterial endotoxins and antigens gain access to portal blood and activate pancreatic macrophages to release inflammatory cytokines like IL-1, IL-6, TNF in necrotizing pancreatic tissues. The inflammatory cytokines are one of the major reasons for chronic pancreatitis and subsequently tumorogenesis in pancreas. In the present scenario there is no effective screening modality as well as the results of therapies for pancreatic cancer are not satisfactory, therefore the best way to reduce morbidity and mortality is by effective primary prevention.

Therefore, the use of commensal microbiota such as probiotics is increasing in popularity for both prevention and treatment of pancreatic cancer. Research studies speculated convincing evidence that the functions of the intestinal microflora is positively influenced by probiotics which exert a therapeutic effect through modification of the composition of indigenous intestinal microflora and its metabolic activity, prevention of overgrowth and colonization of pathogens, and stimulation of the immune system [11]. Probiotic bacteria may be defined as "live microorganisms which when administered in adequate amounts confer a health benefit on the host" [12] and they most frequently belong to the lactic acid bacteria [LAB] category, such as Lactobacillus spp. and 
Bifidobacterium spp. [13]. They are usually ingested as a part of dietary supplements or fermented foods. There should be common consensus from experimental findings that probiotics are considered safe for human ingestion with limited or no reported cases of adverse events. Despite the great number of studies in the literature, the precise mechanisms by which probiotics may prevent pancreatic cancer still remain not perfectly clear.

Therefore, the aim of this review is to underscore the prospects and challenges of the role of probiotics in the pancreatic cancer. The first part presents some of the mounting evidence implicating the role of gut microbiota in human health and epidemiology of the pancreatic cancer. The various risk factors like genetic factors, inflammation, various lifestyle diseases and their contribution toward pancreatic cancer are highlighted and discussed in the second part of the review. The third part emphasizes some of the prospects and challenges confronting research into the role of probiotics in pancreatic cancer and also posits areas of future research.

\subsection{Histological Perspective of Pancreatic Cancer}

The pancreas plays central role in digestive process and a glandular organ of the digestive system consisting of a) an endocrine component which secretes insulin, glucagon and stomatostatins; b) an exocrine component that produces numerous digestive enzymes. Structurally, the pancreatic tissue is composed of functional epithelial cells arranged in acini and islet formations. The acini are manifested for the exocrine function, with digestive enzymes produced within these cells secreted into the acinar lumen and transported to the duodenum through the pancreatic ducts. The islets are responsible for the endocrine activity of the tissue. In order to maintain this cellular architecture, a variety of stromal and supporting cells are present. The stromal components include fibroblasts, pancreatic stellate cells (PSC), endothelial cells, nerves and inflammatory cells. Research findings confirmed that the hormone secretin could stimulate pancreatic secretion that is further modulated by a complex interaction between neural, hormonal and mucosal factors. The alterations in the normal physiological responses by many environmental and genetic factors lead to pathological responses and development of pancreatitis and pancreatic cancer.

\subsection{Epidemiology of Pancreatic Cancer}

Pancreatic cancer is characterized as one of the aggressive metastasis having extremely chemo-resistant tumors and worst prognoses. The relapsed and repeated pancreatic infection as well as inflammation plays dynamic role in the progression of pancreatic cancer. Though other factors also plays contributing role therefore this disease is considered as multi-factorial from evolutionary point of view [14]. Research studies confirmed that the progression of pancreatic cancer have direct relationship from acute pancreatitis (AP) to chronic pancreatitis $(\mathrm{CP})$ and finally its metastasis.

Acute pancreatitis (AP) is a clinical syndrome characterized with acute injury in the pancreas. This is due to the bacterial infection caused by predominately Gram-negative 
strains [15] which further trigger the pathological activation of digestive enzymes that leads to the inflammation and alterations in the vicious cycle of cell signalling. This result in the increased permeability of the gut and subsequent migration of macromolecules such as bacteria, endotoxins and antigens from the gastrointestinal tract to the pancreas causes bacterial translocation (BT) and severe pathogenesis. Various Scientific efforts have been done for the identification of the migratory route of bacteria [16] but still it's a matter of thorough study and hypothetical explanation has been come out. The hypothesis states that it could be a direct transmural migration to the peritoneal cavity or retro peritoneum and then to the pancreas or lymphatic or hematogenous dissemination to the pancreas [17]. This process involves alterations in morphological and functional characteristics such as small bowel hypomotility, rupture of the gut barrier and systemic immunossuppression [18]. Furthermore these kinds of recurrent episodes of pancreatitis lead to chronic pancreatitis (CP) characterized with fibrotic tissue formation and stellate cell activation. Therefore, research findings strongly supports that this hierarchy from acute pancreatitis (AP), recurrent AP and Chronic pancreatitis (CP) to metastasis are the part of the pancreatic cancer continuum.

The pancreatic cancer is characterized with the occurrence of three types of precancerous lesions: pancreatic intraepithelial neoplasia (PanINs), intraductal papillary mucinous neoplasms (IPMN), and mucinous cystic neoplasms (MCN). A number of diverse molecular changes have been manifested after the conversion of these precursor lesions into pancreatic ductal adenocarcinoma (PDAC) [19]. Pancreatic ductal adenocarcinoma (PDAC) is known as pancreatic cancer, is the most well-known exocrine-based pancreatic tumor. Scientific studies indicated that the progression of this malignancy is not solely dictated by the tumor cells themselves, but rather there is melodious synergy between tumor stromal cells with multiple signaling pathways [20]. The aggressive metastasis in the cancer limits its thorough understanding of cellular and molecular mechanisms of initiation and progression therefore, various mouse models have been developed [21] for comprehensive understanding of the complexities of this cancer.

\section{Risk Factors of Pancreatic Cancer}

Pancreatic cancer (PC) is nearly uniformly fatal among all cancers, despite aggressive treatment in the developing and developed countries. Currently, there have been important technological advances in the molecular, pathological and biological understanding of this deadly disease. The lethality of this cancer requires dedicated attention for the causes and modifiable risk factors associated with the onset and the progression. The Figure 1 represents the overview of the various risk factors for the pancreatic cancer.

\subsection{Diet}

Diet plays pivotal role [22] as it modulate the metabolic physiology of the pancreas resulting the release of those relevant factors which promote pancreatic carcinogenesis. 


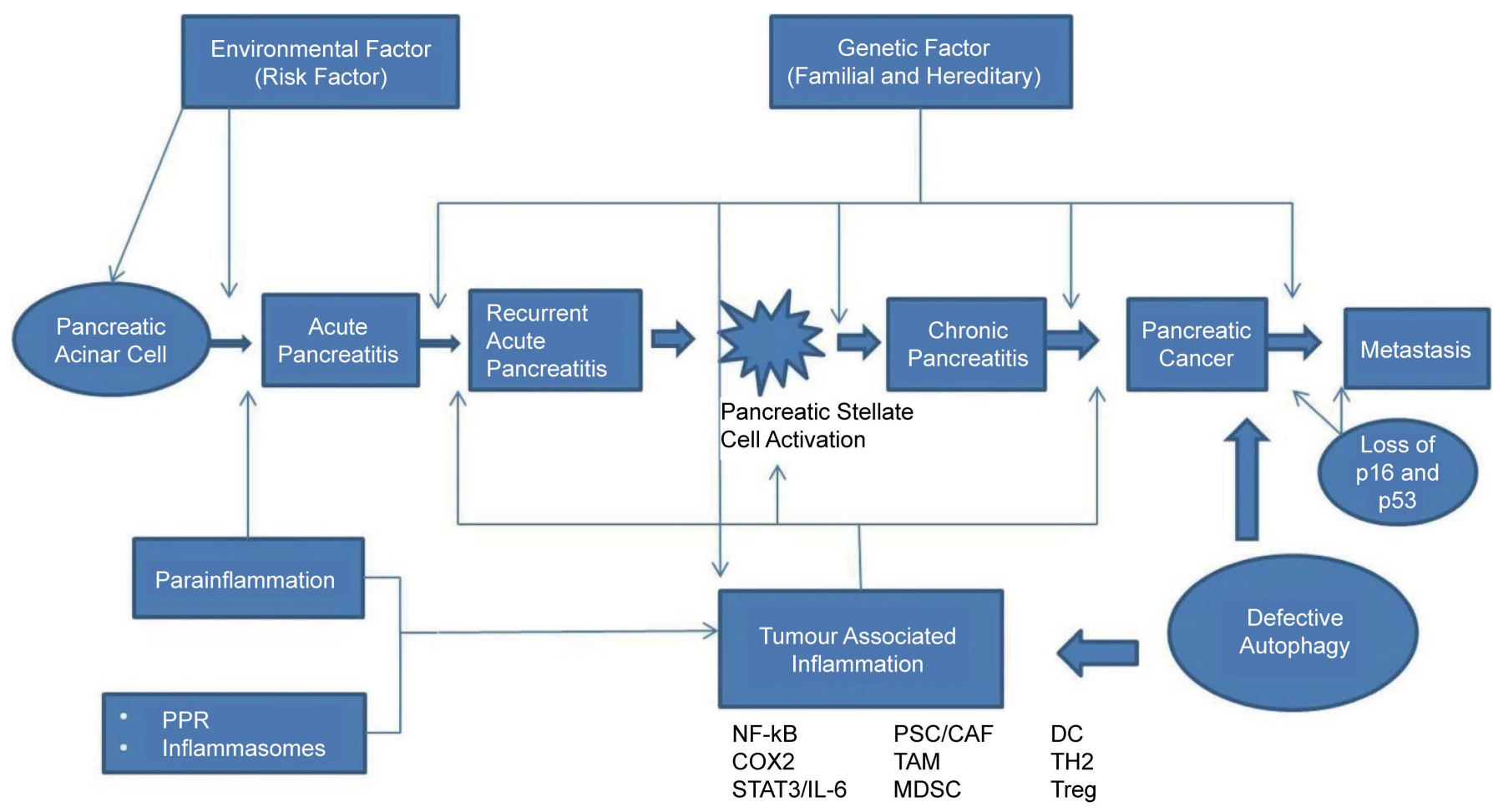

Figure 1. Overview of various risk factors associated with pancreatic cancer.

Research studies confirmed that the consumption of preserved vegetables has higher risk as they contain large quantities of nitrites and nitrates which may serve as substrates for endogenous formation of N-nitroso compounds [23]. There has also been well documented that consumption of eggs and dairy products [24] butter and margarine [25] rice and white bread [26] in excess can also promote this cancer. There have been increased risks associated with high intake of fat and unsaturated fat [27] as well as carbohydrates [28]. These studies confirmed that there is close association between diet and pancreatic cancer and also needs in-depth understanding which paved the way for future investigations.

\subsection{Life Style Choices}

\subsubsection{Consumption of Excess Alcohol}

The consumption of alcohol is increasing globally and considered as one of the pivotal factor for the development of cancer worldwide thus positively associated with pancreatic cancer as well [29]. Various scientific studies have been undertaken to comprehend the effect of alcohol and found that the polymorphisms in genes encoding enzymes for ethanol metabolism (e.g., alcohol dehydrogenases, aldehyde dehydrogenases, and cytochrome P450 2E1), folate metabolism and DNA repair is responsible for the cancer development. The association between alcohol use and incidence or mortality of pancreatic cancer was confirmed by 60 analytical epidemiologic studies [30] including 13 prospective cohort studies. Some research groups [31] [32] prospectively examined the relation between alcohol use and risk of pancreatic cancer among 470,681 partici- 
pants who were aged 50 - 71 years in 1995-1996 in the US National Institutes of HealthAARP Diet and Health Study. The authors identified 1,149 eligible exocrine pancreatic cancer cases through December 2003. Scientific evidence suggests that heavy alcohol consumption induces chronic calcifying pancreatitis which may, perhaps in the presence of other dietary modifiers (e.g., high fat), lead to pancreatic cancer. Therefore, heavy alcohol consumption is the most common cause of both acute and chronic pancreatitis [33] [34] therefore it play significant role in pancreatic cancer development.

\subsubsection{Smoking}

One of the most well established risk factor for pancreatic cancer is cigarette smoking. The amount of dose and the time of exposure of cigarette smoke have substantial impact on the progression of pancreatic cancer that has been confirmed from various epidemiological studies [35]. The results of meta-analysis of tobacco risk and pancreatic cancer from 82 studies revealed that there was an estimated 75\% increased risk for pancreatic cancer in smokers versus non-smokers. The scientific literature also supported the fact that smoking cessation can reduce this risk by up to $50 \%$, at all age groups but is particularly important for the prevention of early onset of pancreatic cancer [36]. The cigarette smoke comprises well known sixty carcinogens, that is responsible for the initiation of tumrogenesis [37]. A lot of scientific efforts have been carried out for understanding the mechanism of this initiation and it was found that due to the formation of DNA adducts resulting in mutations in a number of vital genes implicated in tumorigenesis. One of the vital gene is KRAS, which is mutated in nearly all pancreatic cancers [38] [39]. This protein recognized as binary molecular "switches" to activate various cell signaling pathways. The various signals came from extracellular environment in the form of growth factors, cytokines, damage molecules (DAMPs), hormones activate Kras. These molecules indirectly interact with guanine nucleotide exchange factors (GEFs), replacing GDP for GTP and switching Kras "on" and subsequently leads to the down regulation of signaling pathways including STAT3, NF- $\kappa$ B, COX-2 and Scr. This interaction leads to the generation of inflammatory mediators that further activate Kras through positive feedback and favors malignant growth.

\subsection{Aging}

The technological interventions in the improvement in health care as well as living standards increase the elderly populations at global level. Astonishingly, it is said that "there is an elegant interplay between pancreatic cancer and ageing and seems to be unlikely bedfellows" therefore, aging is considered as one of the predominant risk factor for pancreatic cancer. It was hypothesized from the global survey that more than $50 \%$ of the diagnosed patients with cancer are older than 60 years, and more than one third are over the age of 70. The alterations in cell-autonomous mechanisms that reduce the cellular stress, damage and dysfunction are the common etiologies of aging and cancer. More comprehensive studies have been undertaken to investigate the correlation of molecular mechanism of aging with pancreatic cancer and found that erroneous repair 
of DNA damage manifested with severe mutations leading to altered gene function, results in pancreatic carcinogenesis. Among various genes investigated, p53 plays dynamic role in the tumor suppressive DNA damage response (DDR) and is mutationally inactivated in approximately $50 \%$ of human cancers. This is experimentally validated by Sato et al. [40]. This research group used mouse models to study the expression of p53 mutations in paraffinized tumors by using monoclonal antibodies. The results showed over expression of this gene and were more prominent in older patients. These studies concluded that p53 mutations may be induced with aging and responsible for onset of pancreatic cancer. However, further studies will be needed to demonstrate whether or not various agents targeting signal transduction pathways or nuclear transcription factors are useful for elderly patients with advanced pancreatic cancer.

\subsection{Life Style Diseases}

\subsubsection{Diabetes}

Diabetes mellitus has been recognized as one of the third modifiable risk factor for the development of pancreatic cancer. Numerous studies confirmed that the prevalence of diabetes in pancreatic cancer has varied considerably (from $4 \%$ to $65 \%$ ). Though there is a strong association between pancreatic cancer and diabetes but it is yet to be in intensive speculation that why pancreatic cancer causes diabetes and how diabetes can be an early manifestation of pancreatic cancer? Peripheral insulin resistance, hyperinsulinemia, hyperglycemia and inflammation have been well investigated for the contribution of diabetes-associated pancreatic cancer [41]. Though insulin resistance is also found in non-diabetic or glucose intolerant pancreatic cancer patients [42] [43] but majority of the research studies confirmed that pancreatic carcinoma are causally related to the insulin resistance. The studies were also supported by Basso et al. [44] who obtained a $2030 \mathrm{MW}$ peptide from the sera of patients with pancreatic cancer and considered that this peptide can be a putative diabetogenic factor associated with it.

More recent studies suggested that anti-diabetic regimens may independently modify the risk of pancreatic cancer due to the effect of stimulation on the pancreatic beta and islet cells [45]. Currently, fourteen classes of drugs have been used in the treatment of diabetes and some have been linked to the increased risk of pancreatic cancer. The increased risk of cancer has been visualized with sulfonylureas. These classes of drug are the effective during the early stages of diabetes and directly modify the potassium channels in pancreatic cells which further stimulate the secretion of insulin. The concerning risk of pancreatic cancer is validated by the case control study reported by Monami and colleagues which included 1340 diabetic patients followed up for an average of 75.9 months. The 112 patients who developed cancer also had a greater length of exposure to a sulfonylurea compared with the control group of diabetic patients [46].

Furthermore, another class of the drug commonly known as "incretin family" that includes insulin secretagogue (Meglitinide) and Glucagon-like peptide. Meglitinide that stimulates endogenous secretion of insulin by inhibiting potassium channels in the pancreas on a different site from sulfonylureas. Glucagon-like peptide (GLP)-1 is an 
incretin hormone that is secreted by L-type endocrine cells in the distal ileum after the ingestion of food [47]. This peptide stimulates the secretion of insulin as well as promotes beta-cell proliferation and survival [48] by the binding to cell membrane GLP receptors. GLP-1 agonists bind to GLP receptors to restore beta-cell sensitivity to glucose. Native GLP-1 is normally degraded by the enzyme dipeptidyl peptidase (DPP)-4. Drugs that inhibit DPP-4 have been developed and are currently being used as treatment for type 2 diabetes. Currently used drugs as GLP-1 agonist are sitagliptin, exenatide's. FDA reported 88 cases between October 2006 and February 2009 of acute pancreatitis, including 2 cases of necrotizing hemorrhagic pancreatitis, in patients receiving sitagliptin [49] Based on these observations FDA released a safety alert and subsequently the manufacturer updated exenatide's prescribing information to include the precaution of acute pancreatitis [50]. Because pancreatitis is a known risk factor for pancreatic cancer, there is concern that long-term use of a GLP-1 agonist increases pancreatic cancer risk.

Another important class of drug that has been used to treat diabetes is to take exogenous insulin in the form of insulin analogue. It increases the uptake of glucose into the cells, stimulates glycogen synthesis and inhibits glucagon. The drug used currently is insulin aspart, and insulin glargine as fast-acting insulin analogues. The increased risk of pancreatic cancer was confirmed by German cohort study published in 2009 [51]. They studied 127,031 patients and concluded that that there was an association between incidence of malignancy and insulin dose for all insulin types; however, in comparing aspart, and glargine to human insulin only glargine was found to have a higher dose dependent risk for carcinogenesis.

\subsubsection{Obesity}

The prevalence of the obesity is rising world-wide and its coherence with pancreatic cancer is becoming more apparent. Research findings revealed convincing evidence that an augmented risk of pancreatic cancer is associated with those people who are obese or have high body mass index (BMI). In 2007, the results from 38 studies conducted by World Cancer Research Fund Panel concluded that there is a "convincing increased risk" of pancreatic cancer related to body fatness and a "probable increased risk" with abdominal fatness [52] [53]. The mechanism of the complexity of obesity with cancer is clearly understood by tumor promoting inflammatory and hormonal factors associated within adipose tissue. The enhanced levels of inflammatory cytokines such as TNF- $\alpha$, IL-1 $\beta$, IL- 6 , and IL-18 has been observed within adipose tissue and also systemically through inflammasome activation in macrophages [54] which further augment the inflammation. The obesity also leads to the activation of pro-inflammatory hormone leptin and decreases adiponectin, its anti-inflammatory counterpart [55]. Furthermore, the anomalies prevalent in the energy balance factors due to the stagnant life style and intake of high calorie food also aggravate the occurrence and progression of pancreatic cancer. Therefore, this association between pancreatic cancer and obesity may provide to exploit a suitable platform for the futuristic investigations for preven- 
tive and intervening measures to modify this factor at personalized level.

\subsection{Genetic Factors}

Pancreatic cancer, like all cancers is a fundamentally genetic disease caused by both inherited and acquired genetic mutations. Inherited genetic variation plays an important role in both the familial and non-familial (sporadic) occurrences of pancreatic cancer. It is estimated that $5 \%-10 \%$ of pancreatic cancer patients have a family history of pancreatic cancer [56]. While the genetic mutations responsible for the majority of the clustering of pancreatic cancer in families have yet to be identified, several pancreatic cancer genes have been established, including both high-penetrance genes such as BRCA2 [57], STK11 [58], p16/CDKN2 [59] and PALB2 [60] and low-penetrance genes such as the $\mathrm{ABO}$ blood group locus [61]. However, the genetic basis of the majority of pancreatic cancer remains unclear, as these established high-penetrance genes explain only $10 \%-15 \%$ of the familial aggregation of pancreatic cancer. Research studies also speculated that number of inherited cancer syndromes increase the risk of pancreatic cancer. These include the breast cancer syndrome, familial atypical multiple mole melanoma syndrome (FAMMM), Lynch syndrome and the Peutz-Jeghers syndrome. Recent technological improvements in genotyping and genome sequencing have accelerated the pace at which new pancreatic cancer genes have been discovered and could unravel the story of pancreatic cancer.

\subsection{Dysregulation of Zn Metabolism}

Zinc ( $\mathrm{Zn})$ is the second most essential trace element required for cellular homeostasis and its deficiency leads to impaired DNA and protein synthesis, growth retardation, decreased food intake, skin allergies, malfunctioning in immune system. The compartmentalization of $\mathrm{Zn}$ into various intracellular organelles and its regulation through $\mathrm{Zn}$ transporting mechanisms has proven the fact of complexity of $\mathrm{Zn}$ homeostasis in human body [62]. The two solute-linked carrier (SLC) gene families were identified in zinc transport, SLC30, which encodes for zinc transporter ( $\mathrm{ZnT}$ ) proteins, transport $\mathrm{Zn}$ from the cytoplasm and SLC39, which encodes for Zrt-, Irt-like proteins (ZIP) transport $\mathrm{Zn}$ into the cytoplasm [63]. The role of Zinc Transporters proteins are depicted in Figure 2.

Research studies confirmed that various functions of pancreas are modulated by $\mathrm{Zn}$. One of the important functions is to modulate glucagon secretion [64]. The ZIP transporter proteins (Zip1, Zip10 and Zip14) are expressed in pancreatic $\alpha$-cells and $\mathrm{Zn}$ is providing an "off-switch" for glucagon release from the pancreatic $\alpha$-cell during glucose deprivation [65]. Another function is to regulate insulin biosynthesis within the pancreatic $\beta$-cell where proinsulin is transported to the Golgi apparatus and is subsequently incorporated into $\mathrm{Zn}$ rich secretory granules [66]. $\mathrm{Zn}$ also plays dramatic role for maintaining the functional structure of insulin in which the two $\mathrm{Zn}$ ions associate with 2 insulin dimers, which subsequently combine with an additional insulin dimer to form functional hexameric unit [67]. Therefore, $\mathrm{Zn}$ dyshomeostasis, plays an intricate role in 


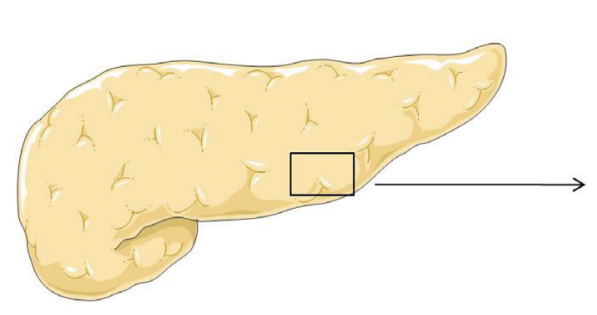

Pancreas

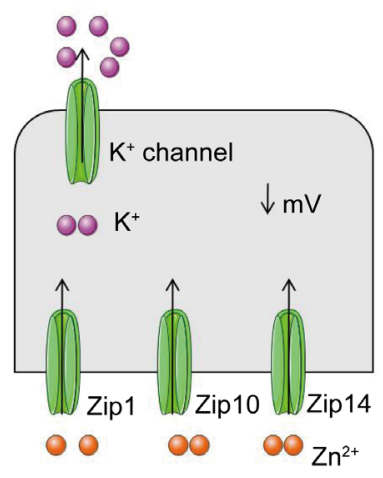

Alpha cells

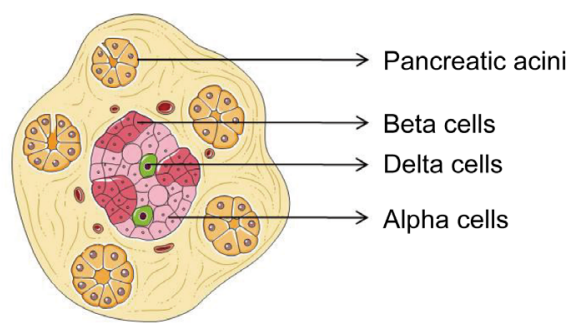

Pancreatic islets

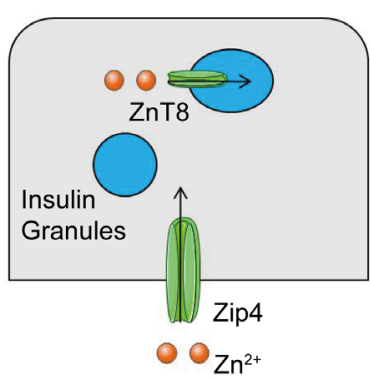

Beta cells

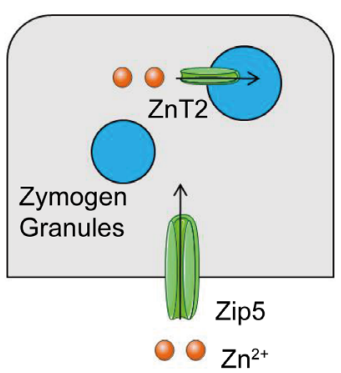

Acinar cells

Figure 2. Role of $\mathrm{Zn}$ transporter proteins in Pancreas.

the pathology of both type 1 and type 2 DM. [68]. It has been evidenced from research studies that the presence of $\mathrm{Zn}$ is crucial for tumor growth and progression as it imparts critical component for many enzymes such as carbonic anhydrase and matrix metalloproteinases (MMPs), which are directly involved in cancer risk in the form of hypoxia, angiogenesis, cell proliferation, and metastasis [69]. The aberrant up-regulation of ZIP4 (SLC39A4) contributes significantly to the progression and pathogenesis of pancreatic cancer by facilitating increased intracellular accumulation of $\mathrm{Zn}$.

Li et al. [70] elegantly observed over expression of Zip4 protein in $94 \%$ of clinical pancreatic adenocarcinoma specimens compared with surrounding normal tissue and that malignant cells had significantly higher Zip4 expression compared with normal pancreatic ductal epithelial cells. That has been also validated with induced expression of Zip4 which increased cell proliferation invitro and significantly increased pancreatic tumor volume by $\sim 13$-fold invivo using a nude mouse model. Further studies have been done at molecular level which clearly indicated that there are several intermediate signaling pathways modulated by Zip4 over expression that significantly increases neuropilin-1 expression, vascular endothelial growth factor, and matrix metalloproteases. Zhang et al. [71] found that Zip4 over expression causes increased IL-6 transcription through cAMP response element-binding protein. Furthermore, IL-6 activates STAT3, which increases expression of cyclin D1, increasing cell proliferation and tumor progression. Therefore, it plays dynamic role in the pathology of pancreatic carcinogenesis.

\subsection{Inflammation}

Inflammatory processes have emerged as key mediators of pancreatic cancer develop- 
ment and progression therefore this disease is characterized as quintessential example of an inflammation-driven cancer. The epidemiological data as well as comprehensive studies from preclinical and clinical models has profoundly supported this fact. In recent years, much effort has been given to identify the underlying mechanisms that contribute to inflammation-induced tumorigenesis. Inflammation that is a result of cellular stress and malfunction has been termed "parainflammation" and is hypothesized to contribute to cellular adaptation to the cancerous environment [72]. Many cell signaling pathways have been identified and they contribute to the formation of inflammatory molecular networks. These signaling pathways not only function as biological regulator along, but also interact with each other and their cross-talk effects were already investigated. Under normal circumstances, inflammatory molecular networks function well in a balanced way, maintaining the homeostasis. Once the chronic inflammation was induced by the alteration of signaling networks resulted from tissue injury and/or infection, aberrant somatic mutations or epigenetic modifications may occur, increasing the risk of carcinogenesis. Therefore, Inflammation is considered both as a risk factor for and as a consequence of oncogenesis in pancreatic cancer. A more detailed discussion of inflammation and its correlation in pancreatic cancer follows in section Inflammation and Figure 3 represents the overview of the role of inflammation in pancreatic carcinogenesis.

\subsubsection{Effect of Inflammation on JAK-STAT3 Signaling Pathway}

Research studies confirmed that the high level of STAT3 has been associated with advanced tumor stage and decreased survival in patients with pancreatic ductal adenocarcinoma (PDAC). Constitutively active Stat 3 has been observed in $30-100 \%$ of human pancreatic cancer samples [73]. STAT3 has synergistic interplay with JAK family. JAK family contains four members including JAK1-3, molecules belonging to tyrosine kinase (PTK) family [74]. The binding of IL-6 to its receptor consequently leads to the depolymerization of the intracellular portion of the receptor in which JAK binds to the box function region of the receptor dimer and get phosphorylated and activated. STATs belong to substrates of JAK, and at the same time are kinds of DNA binding proteins with scr homology 2 (SH2) function domain. STAT can bind to tyrosine site of receptor dimer as well as KLD functional domain of JAK via SH2 domain. JAK phosphorylates tyrosine sites in the $\mathrm{Y}$ function region of STATs, causing STATs activation resulting activated STATs as homologous or heterologous dimmers in the cytoplasm. These dimers are shifted to the nuclei and activate a variety of targeted oncogenes, leading to malignant progression of PDAC [75].

\subsubsection{Effect of Inflammation on Autophagy and Inflammasomes}

Defective autophagy is a key component in promoting persistent inflammatory responses [76]. Accumulation of p62 through faulty autophagy can ultimately lead to activation of the transcription factor NF- $\kappa \mathrm{B}$, a critical mediator of inflammation [77]. Arrested autophagy also leads to elevations in reactive oxygen species (ROS), due to lack of removal of damaged mitochondria. ROS can activate inflammasomes, a large intra- 


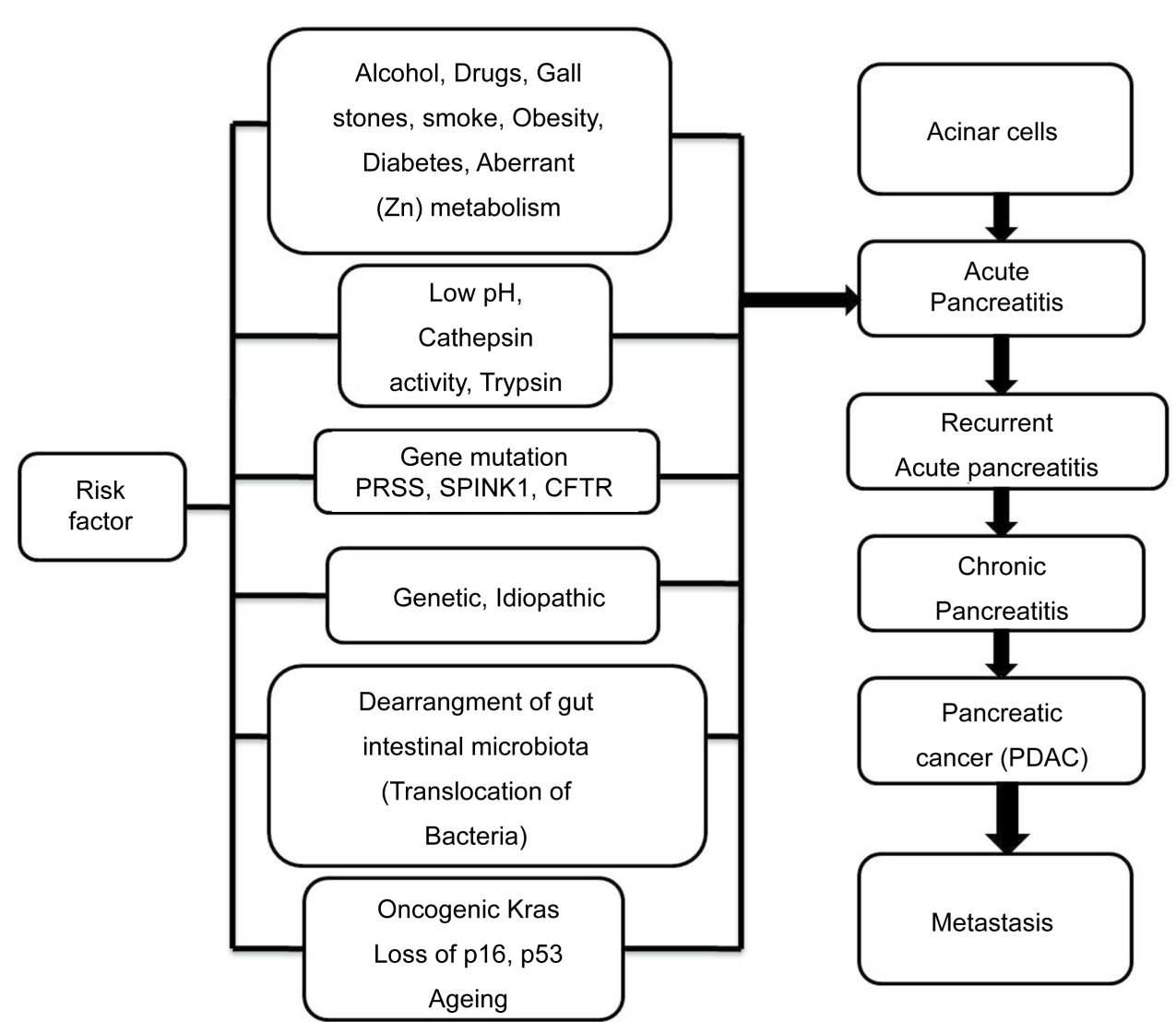

Figure 3. Role of inflammation in pancreatic carcinogenesis.

cellular multiprotein complex that play a central role in innate immunity [78] [79] and eliminated through autophagy. The lack of autophagy in pancreatitis maintains their presence in the cell and hence their participation in the inflammatory process [80]. The impaired autophagy disrupts clearance of apoptotic material from the acinar cell. This leads to secondary necrosis and the release of damage-associated molecular pattern molecules (DAMPs), including nuclear DNA, mitochondrial DNA and ATP. Resident macrophages within the pancreas detect these DAMPs via (i) Toll-like receptor-9 (TLR9) which induces NF- $\kappa$ B activation and pro-IL- $\beta$ transcription and (ii) plasma membrane purinergic receptor P2X7, which mediates IL- $1 \beta$ maturation through inflammasomal components Nlrp3-ASC. Subsequent generation of IL- $1 \beta$ results in further cytokine production, recruitment of immune cells and pancreatic apoptosis [81]. PDAC cells have higher basal levels of autophagy than most other types of tumor cells, facilitating their survival under stressful conditions including nutrient deprivation, hypoxia, metabolic stress and chemotherapy [82].

\subsubsection{Effect of Inflammation on NF- $\kappa$ B Signaling}

The nuclear factor- $\kappa \mathrm{B}$ (NF- $\kappa \mathrm{B}$ ) proteins constitute a family of transcription factors most commonly associated with mediating inflammatory responses. NF- $\kappa \mathrm{B}$ family contains 5 members, namely p65 (RelA), p50 (NF- $\kappa$ B1), p52 (NF- $\kappa$ B2), RelB, and cRel. These proteins have a same amino terminal, which is composed of about 300 amino 
acid residues, called Rel homology domain (RHD), with DNA binding site and depolymerization site inside. $\mathrm{I} \kappa \mathrm{B}$ is a kind of repressor protein of $36 \mathrm{kDa}$, which can interact with the amino acid residues of RHD, masking the translocation signal nuclear sequence in RHD, and preventing NF- $\kappa \mathrm{B}$ translocation to preserve it in the cytoplasm. After receiving appropriate stimulatory signal $\mathrm{I} \kappa \mathrm{B}-\alpha$ is phosphorylated and destined for degradation. This enables NF- $\kappa \mathrm{B}$ movement into the nucleus to regulate transcription of its target genes [83] where it increases the expression of pro-inflammatory mediators. Cytokines and adhesion molecules attract additional immune cells causes inflammation which directly leads to promotes chronic pancreatitis. The NF- $\kappa$ B subunit RelA has been shown to be constitutively activated in PDAC cells but not in normal pancreatic tissues [84]. Other NF- $\kappa$ B subunits, including p105, p100, and $c-$ Rel have been found to have increased expression in certain PDAC cell lines [85].

The levels of NF- $\kappa$ B have also been increased with trypsinogen activation [86]. The anomaly in calcium levels and activation of PKC isoforms have been implicated in NF- $\kappa$ B activation. Support for such conclusions come from the findings that chronic pancreatitis greatly increases the risk to the development of PDAC [87].

\subsubsection{Effect of Inflammation on COX-2 Expression}

The enzymes cyclooxygenase 1 and 2 (COX-1and2) are important rate limiting factors in prostaglandin production. The inflammation leads to up-regulation of COX-2 and in $\mathrm{CP}$ it is over expressed in acinar, islet and ductal cells. The presence of COX-2 in ductal cells points toward its role in modulating growth factors and cytokines from ductal cells in fibrosis and inflammatory pathways [88]. COX-2 has been linked to development of pancreatic dysplasia and PDAC and may form a potential link between CP and subsequent development of pancreatic cancer. Elevated COX-2 has been associated with pancreatic cancer cell proliferation [89] and tumor growth [90] [91].

\subsection{Aberrant Calcium Signaling}

Calcium homeostasis plays an important role in survival and normal functioning of cells and is achieved by various calcium channels or pumps associated with the plasma membrane. Scientific studies suggested that cancer cells explicitly use glycolytic ATP as the energy source for their growth. The glycolytic ATP enhances calcium pumps known as plasma membrane calcium ATPase (PMCA) to provide the energy necessary for maintenance of low calcium levels in pancreatic cancer cells. In addition to those endoplasmic reticulum ryanodine receptors (RyR) and plasma membrane store operated calcium channels (SOC) are an important means of elevating calcium in pancreatic acinar cells [92]. Cigarette smoking affects the PMCA activity, therefore it is possible that nicotine-mediated changes in pancreatic acinar cell PMCA contributes to pancreatic diseases as well. The consumption of alcohol as well cigarette smoking affects the calcium homeostasis in pancreatic cells. The conversion of alcohol to fatty acid ethyl esters (FAEEs) via non-oxidative pathways induces the release of calcium from intracellular stores and premature trypsinogen activation [93]. In addition to that free radi- 
cals generated through FAEEs have been shown to damage mitochondrial membranes causing ATP depletion [94] [95]. This alters the bioenergetics of acinar cells and favors necrosis over apoptosis.

\section{Probiotics in Pancreatic Cancer Prevention: The Prospects}

Research has been conducted to explore the role of commensal microbiota in pancreatic cancer prevention. The convincing aspects of probiotics in alteration of the intestinal microflora, inactivation of carcinogenic compounds, competitive exclusion with pathogenic microbiota, improvement of the host's immune response, anti-proliferative effects via regulation of apoptosis and cell differentiation metamorphosize the healthy metabolism of the organism. The role of probiotics is still long way to go for the effective treatment of this noxious form of cancer. The various factors described above reveals the causative and risk factors of pancreatic cancer and there is an elegant synergy between these risk factors suggests a common pathway for carcinogenesis of the pancreas. Therefore, we tried to correlate the impact of probiotics on various risk factor associated with pancreatic cancer which can prevent the onset of tumuorogenesis.

\subsection{Modulation of Probiotics by Dietary Components}

Diet plays significant role in pancreatic carcinogenesis [96] although the specific components and mechanisms are ongoing area of research. Scientific literature proposed strong evidence to support the preventive aspects of probiotics. The ingestion of meat which is cooked at high temperature leads to the conversion of heterocyclic aromatic amines [HCA], [97] [98] to active derivatives such as the pyrolyzates 3-amino-1,4dimethyl5H-pyrido-[4,3-b]indole [Trp-P-1], 3-amino-1-methyl-5Hpyrido-[4,3-b]indole [Trp-P-2], 2-amino-3-methylimidazo [4,5-f] quinoline [IQ], 2-amino-1-methyl-6-phenylimidazo [4,5-b]pyridine [PhIP], 2-amino-3,4-dimethylimidazo[4,5-quinoline [MeIQ], and 2-amino-3,8-dimethylimidazo[4,5-f]quinoxaline [MeIQx] [99] [100] that induce tumorigenic mutations. The inherent and marvelous properties of LAB and other commensal bacteria to bind or metabolize these mutagenic carcinogens [101] [102] were further confirmed by the research studies. The studies led to the conclusive remarks that the binding or degradation of HCA by probiotics could be one of the main mechanisms of removing carcinogens out of the human body. Different research groups proposed supportive evidence to prove these facts. In continuation of this Orrhage et al. [103] confirmed the binding of mutagenic HCA by some species of LAB which was formed during the cooking of protein-rich food. Further, Sreekumar and Hosono [104] studied the binding of other nitroso compounds like Trp-P-1 and TrpP-2 by the different strains of L. gasseri and B. Longum. Zhang et al., reported that there was reduction in the genotoxcity of Trp-P-1 after binding with the cell fraction of L. acidophilus and Bifid. spp. [105]. Rhee et al., 2001 reported the antimutagenic fractions from $L$. plantarum KLAB2 and its effect against N-methyl-N'-nitro-N-nitrosoguanidine on $S$. enterica TA100 cells. They confirmed that this anti-mutagenicity is conferred by three extracellular glycoproteins [106] present in the bacterial cell wall. 
Astonishingly, research investigations revealed that the probiotics can also be used for alleviation of the fungal mycotoxins and toxic heavy metals that can be the potential factors of pancreatic carcinogenesis. Researchers investigated the alleviation of fungal mycotoxins invitro from aqueous solutions [107] [108] as well as cyanotoxins like microcystin-LR, lead and cadmium [109] [110] by Propionibacteria a well known dairy probiotic. Therefore, there could be the probability of reduction in the pancreatic cancer risk by lowering the bio-availability of these carcinogenic compounds. However, some studies pertaining to the metabolic degradation of carcinogenic afatoxin B1 (AFB1) by $L$. rhamnusos GG was also reported. The scientific literature also evidenced the ability of $S$. cerevisiae CECT 1891 and L. acidophilus 24 to remove fumonisin (B1) from liquid medium [111] [112]. The above mentioned studies indicated that the detoxification of dietary mutagenic compounds may be one of the main mechanisms by which commensal microbiome antagonize the onset of PC. Though, more comprehensive studies are required to better clarify the interaction between dietary factors and pancreatic cancer.

\subsection{Effect of Probiotics on Life Style Diseases}

In the recent scenario, obesity and diabetes is considered as pandemic which is tightly linked to the sedentary lifestyle and energy imbalance between intake and expenditure. Recent studies suggested that probiotics modulate the health of gut microbiota and various metabolic functions. Therefore, various mouse models as well as human studies have been conducted for assessing the efficacy of probiotics and their effects on life style diseases like type 2 diabetes and obesity. The high fructose-fed rat model was chosen for evaluating the efficacy of probiotics in alleviating these metabolic disorders. The studies confirmed that utilization of $L$. reuteri as probiotic supplement significantly reduced the elevated levels of serum glucose, insulin, leptin, C-peptide, glycated hemoglobin, liver injury markers and lipid profile parameters [113]. The administration of $L$. plantarum, L. acidophilus, or L. casei in high-fat diet-induced obese mice and alloxaninduced diabetic rats, have resulted in reduction of body weight, hyperglycemia, epididymal fat, triglyceride, insulin and leptin, lipase activity, non-esterified fatty acids, triglyceride, low density lipoprotein (LDL)-cholesterol, LDL/HDL (high density lipoprotein) ratio and adipocyte IL-1 $\beta$ mRNA expression [114] [115] [116] [117]. The positive effects on the pancreas, liver and kidney were observed with the significant enhancement in HDL-cholesterol, immunological parameters with the supplementation of this LAB. Recently, L. rhamnosus and L. gasseri were also shown to exert anti-diabetic and anti-obesity effects in mice fed with high-fat or high-sucrose diet. The changes in metabolic parameters i.e. attenuated weight gain, reduced serum levels of leptin and insulin, improvement in insulin sensitivity, increased adiponectin production, down-regulated expression of hepatic gluconeogenic genes, up-regulated expression of hepatic fatty acid oxidative genes, and increased skeletal muscle glucose transporter (GLUT) 4 mRNA expression [118] [119] have been observed. Recently Zhang et al., reported that the supplementation of probiotic have capacity to modulate the gut microbial popula- 
tion, improved glucose tolerance, restored the expressions of GLUT4, PPAR-gamma and lipogenic genes as well as reduced concentrations of pro-inflammatory markers such as interleukin 6 (IL-6) and TNF-alpha in high fructose-fed rats [105]. Ejtahed et al., conducted a clinical trial on humans (type 2 diabetic patients) to compare the effects of conventional and probiotic combination (Lactobacillus and Bifidobacterium) yogurts on lipid abnormalities. They concluded that the consumption of probiotic yogurt reduced the concentrations of LDL cholesterol and total cholesterol [120]. The elimination of atherogenic indices as well as improvement in the glycemic control was also reported [121]. The beneficial effects of consumption of multispecies probiotic supplements on insulin resistance and metabolic profiles including high-sensitivity C-reactive protein (hs-CRP) have also been reported in diabetic patients [122]. Research findings also reported the reduction in body weight, waist and hip circumference by the supplementation of L. gasseri in obese individuals [123] [124]. Though probiotics confers beneficial effects by modulating the life style diseases but still extensive research is needed to find better ways of prevention of pancreatic cancer by modulation of lifestyle.

\subsection{Effect of Probiotics on Bacterial Translocation}

The balanced intestinal ecological environment is maintained by the protective effect of probiotics. The disruption of the balance of intestinal bacterial microflora may increase the incidence of bacterial translocation by modifying intestinal barrier function. That bacterial translocation leads to the aggravated inflammation causing $\mathrm{CP}$ and pancreatic cancer. There is convincing evidence from the experimental studies done in animals for validation of the stabilization of the intestinal barrier by probiotics [125] [126] [127]. The thorough investigations and conclusive remarks came from the studies done by Olah et al. [128]. They reported that the treatment with L. plantarum 299 to the patients with acute pancreatitis had lower incidence of pancreatic sepsis and needed less surgical interventions compared with control patients. The mode of administration of probiotics were also evaluated for their efficiency and studies conducted by Olah and Rhomics [129]. They concluded that enteral nutrition is better utilized compared by parenteral route and reduced the severity of fibrosis, acinar cell loss, oedema, parenchymal necrosis, inflammation and perivascular infiltration of PMNL, inflammation and perivascular infiltration of MNL, ductal damage, atypical reactive regeneration and vacuolization that prevents pancreatic cancer. In addition to that, clinical studies evidenced that the incorporation of synbiotics with multiple LABs and prebiotic fibres for the treatment of severe acute pancreatitis significantly reduced the mortality. Research studies also confirmed that probiotic $S$. boulardii with concomitant addition of antibiotic ciprofloxacin reduces the histopathological scores of acute necrotizing pancreatitis.

\subsection{Effect of Probiotics on Oxidative Stress}

The abnormal formation of reactive oxygen/nitrogen species leads to "oxidative stress" inside the living cell. This formation leads to the unprecedented damage in lipids, nuc- 
leic acid, carbohydrates and proteins of cells and tissues. Therefore, an aberrant production of oxidative stress has crucial role in the pathogenesis and development of malignancy. Though, scientific data pertaining to the anti-oxidative properties of LAB is limited but certain progress has been done in recent years [130]. There is a strong correlation between pancreatic cancer and oxidative stress. Rau et al., 2000 [131] reported the amelioration of experimental pancreatitis in rat model by using probiotics. Furthermore, Lutgendorff et al., 2008 reported that probiotics enhanced the biosynthesis of glutathione [132] and reduce inflammation and acinar cell injury and ameliorated experimental pancreatitis, by reduction in oxidative stress. The scientific studies also proved that reduction in pancreatic DNA damage and its associated effects in CP were observed by treatment with probiotics [133] which led to the prevention of pancreatic cancer. Though, more rigorous studies will be required to investigate the potential effects of probiotics as anti-oxidative role that can be the one of the great solution for combating this noxious form of cancer.

\subsection{Effect of Probiotics on Modulation of Immune System}

The immunity of an individual is well correlated with healthy metabolism and ability to combat with foreign invaders. The immune system plays an integral role in the control of tumor promotion and progression. The components of immune system such as antigen-presenting cells [APCs], and different subsets of T cells, B cells and natural killer [NK] cells has an elegant interplay and cross-talk for the generation of an effective antitumour immune response [134]. Recent scientific investigation has supported the immunomodulatory role of probiotics that leads to a new paradigm shift in cancer prevention and therapeutics [135]. The initial study supporting this fact was documented by Matsuzaki et al., and they suggested that there were strong suppressive effects of chemically induced carcinogenesis as well as strong anti-metastatic effects on transplantable tumor cells by $L$. casei shirota (LcS). The enhanced production of several cytokines, such as IFN- $\gamma$, IL- $1 \beta$ and TNF- $\alpha$, leading to the inhibition of tumor growth and increased survival [136] has been observed with the intra pleural administration of LcS into tumor-induced mice. The similar results was observed by Lee et al. (2004) [137] and the authors reported that the administration for four weeks of $L$. casei YIT9029 and B. longum HY8001, increased the survival rate of mice injected with tumor cells. The increased survival was well correlated with an increase in cellular immunity. Various scientific studies proposed different conclusive studies for identifying the mechanism of the immunomodualtory properties of probiotics. In continuation with this, Goh et al., 2009 investigated the imunomodulatory role of $L$. acidophilus and found that there was profound interaction between immune cells and cell surface components such as lipoteichoic acid (LTA), a zwitterionic glycolipid found in the bacterial cell wall that further induce the production of anti-inflammatory and regulatory cytokines having anti-tumourogenic effect. [138]. Moreover, the preventive effect was reported in which it was concluded that LTA can stimulate DCs through Toll-like receptor 2, resulting in cytokine release [139]. Research studies also evidenced that some 
specific Lactobacillus species can stimulate DCs to produce IL-12 and regulatory, inflammatory cytokine IL-10 [140] [141].

More recently, oral feeding of LcS significantly enhanced NK cell cytotoxicity which delayed tumor onset or suppressed tumor incidence [142]. The enhanced production of TNF- $\alpha$ and NO, leads to the cytotoxicity of tumor cells by the administration of butanol extract of $B$. adolescentis [143]. Research studies also speculated that incorporation of probiotics in the diet can also have substantial impact on cell signaling system. L. reuteri may prevent carcinogenesis via downregulating NF- $\kappa \mathrm{B}$-dependent genes which regulate cell proliferation (Cox-2, cyclin D1) and survival (Bcl-2, Bcl-xL) [144]. In addition to that $L$. reuteri suppressed tumor necrosis factors (TNF)-induced NF- $\kappa$ B activation including $\mathrm{NF}-\kappa \mathrm{B}$ dependent reporter gene expression in a dose- and time-dependent manner to slow down cancer cell growth.

In recent studies, one of the crucial impacts of bacterial translocation is to severely infect the pancreas by pathogenic bacteria Helicobacter pylori. An antigenic peptide of $H$. pylori was identified in patients with autoimmune pancreatitis and pancreatic adenocarcinoma [145] therefore $H$. pylori colonization can be a risk factor for pancreatic cancer [146]. This chronic infection induces the up-regulation of $N F-\kappa B$, central player in inflammation and carcinogenesis. Therefore, it was thought that can probiotics be a viable option for alleviating this infection? Recently, the supplementation of specific strains of probiotics like L. acidophilus, L. casei DN-114001, L. gasseri, and B. infantis was found successful for the eradication of $H$. pylori as compared with antibiotic therapy [147].

\section{Probiotics in Pancreatic Cancer Prevention: The Challenges}

In the current scenario, probiotics has attracted tremendous attention among the research community due to their spectacular advantages in the promotion and improvement of health in living systems. However, there is a wealth of research literature that links the ability of probiotics to modulate the host's metabolism but there is an only limited research on the effects of probiotics on pancreatic cancer prevention or treatment. As pancreatic cancer is the worst among gastrointestinal disorders due to its fast metastasis a number of challenges (issues or questions) still exist. These challenges, which need to be addressed, relate to how the probiotics modulate, influence and interfere with the host's mechanisms to elicit various metabolic effects to combat this form of cancer. The elegant interplay between infammation and carcinogenesis is reflected in the pancreatitis, but the scientific literature apprising the potential role of probiotics in the improvement of chronic pancreatitis as well as the prevention of further metastasis is quite low. These gaps in our understanding, as highlighted above, constitute the main challenges to successfully target the probiotics in the prevention of pancreatic cancer. Therefore, the use of probiotics in pancreatic cancer is still a challenging task for research communities. Here we represent certain critical studies and key questions lead to the role of probiotics in various forms of pancreatitis and their further assessment. 
In our previous discussion, we highlighted the fact that the prime cause of morbidity and mortality in patients with severe acute pancreatitis is the infection of pancreatic necrosis by bacterial translocation. This was conceptualized using different animal models which showed a significantly lower rate of bacterial translocation by using probiotics and this has prompted human trials on this topic. Various scientific efforts were done to investigate the role of probiotics in the prevention of pancreatitis. First scientific report was documented by Olah et al. (2002) [148]. They published the first controlled study on the effect of probiotics in humans. These authors utilized both live versus heat killed LABs for the treatment in human volunteers. The results concluded that there was significant reduction in pancreatic necroses with live Lactobacilli $(5 \%, \mathrm{n}$ $=22)$ compared to heat killed Lactobacilli $(30 \%, \mathrm{n}=23)$ in a group of patients with acute non-biliary pancreatitis. However, the authors have excluded the patients with biliary pancreatitis as well as the trial sample size is very small that's why this study was highly criticized. The same research group in 2008 [129] produced a second trial involving 62 patients with predicted severe pancreatitis. Remarkably, there has been significant reduction in the rate of multiple organ failure (MOF) and septic complications was seen, but unfortunately these differences did not reach conclusive statistical significance. Therefore, the difference in the rate of infectious complications seen in the first trial could not be reproduced but gave the spark that the use of probiotics improved various complications in severe acute pancreatitis.

Furthermore, more comprehensive studies were undertaken by Besselink et al., [149]. They performed Dutch PROPATRIA studies, a double-blind, placebo-controlled randomised multicenter trial. The patients were chosen from 8 Dutch University Hospitals and 7 non-University hospitals. This trial includes 200 patients which were randomly allocated to a multispecies probiotic preparation (Ecologic 641) or placebo. The probiotic preparations was administered twice a day through a nasojejunal tube for 28 days or until discharge. The symptoms of infectious complications which were undertaken for the studies were as follows i.e., infected pancreatic necrosis, bacteraemia, pneumonia, urosepsis, or infected ascites during admission and 90-day follow-up. The probiotic mixture consisted of six different strains of freeze-dried, viable bacteria: $L$. acidophilus, L. casei, L. salivarius, L. lactis, B. bifidum and B. infantis.

The results have severe contradiction as interpreted by Olah et al. The infectious complications observed in $46(30 \%)$ patients in the probiotics group and $41(28 \%)$ of in the placebo group. There was death of $24(16 \%)$ patients in the probiotics group compared with nine (6\%) in the placebo group. After getting the treatment with probiotcs, there was development of bowel ischaemia in nine patients in the probiotics group compared with none in the placebo group. Therefore, the studies conducted to assess the prophylactic aspect of the probiotics in the treatment of severe acute pancreatitis, leads to the increased risk of mortality and failed to reduce the risk of infectious complications.

The differences between these three studies raise certain key questions [150]. Do the species of Lactobacillus and Bifidobacteria and their virulence significantly influence 
the difference between these three studies? Do the variety of prebiotics (oat fiber, beta glucan, and cornstarch) used in these studies made significant difference? Does the multicenter trial have substantial impact or there should be no use of conducting single center trials? The Besselink multicenter trial, however, showed contradictory results which were directly opposite to those from the two earlier studies conducted by Olah et al. [128] [129] and deterred the initiation of other trials on probiotics. Bengmark (2008) [151] raised critical comments on multicentre trial that the choice of LAB and dose of LAB is critical as well as extensive preclinical studies are prerequisite for such kind of conclusive recommendations. However, these issues were addressed by Besselink et al [152] and they agreed that any generalization and recommendations will be reported after investigating the mechanisms by which probiotics exert their positive and negative effects on pancreatitis.

Furthermore, more clinical trials were conducted to further verify the challenging role of probiotics. A meta analysis of four RCTs were reported by Sun et al. (2009) [153]. They reported that the types of probiotics used may lead to significant heterogeneity in the clinical outcomes. The varied effects of various LABs were due to their different adherence sites and divergent immunological functions. The other clinical trial reported the dose of probiotics conferred substantial impact on the disease severity as the same probiotics can have opposite effects at different doses [154]. More recently, a PROPATRIA trial was conducted by Sharma et al. [155]. The ambiguous results were obtained and studies were abandoned.

In addition to that, a recent retrospective analysis [156] suggested that there was no negative impact on patients with predicted SAP although the authors could not revealed any potential benefit of probiotics in this subgroup of patients. Recently, a randomized controlled trial by Cui et al. [157] supported the use of probiotics in combination with enteral feeding. Three modes of feeding i.e. parenteral feeding, enteral feeding or enteral feeding supplemented with Bifidobacterium was administered and compared 70 patients of SAP. They found that the incidence of upper gastrointestinal bleeding, infection and abscess were significantly lower in the probiotic group, and that the length of hospital stay was also significantly shortened in this group. That was again a single centre trail with low patient number therefore appears to the same situation of dilemma of the PROPATRIA trial warranting the cautious application of probiotics in SAP.

The above mentioned discussion was focused on the pancreatitis driven pancreatic cancer. Scientific literature revealed profound evidence of the role of diet in pancreatic carcinogenesis. Till date the evidence is inconclusive due to synergistic factors, such as smoking status, physical activity and distance of habitat from the equator, obesity, $\mathrm{ABO}$ blood group and diabetes. Though the Lactobacillus species considered as potential beneficiary to the host but certain clinical studies have envisaged that gut Lactobacillus species were found with increased BMI and glycemia in healthy and elderly adults. Literature studies also revealed that certain bacterial species, such as $L$. reuteri, are found in large quantities in obesity while others, such as B. animalis are associated with nor- 
mal weight [158]. This suggests that the gut microbiota composition is linked to normal body weight and obesity at the species which can be the driving factors for the pancreatic cancer. The lack of large randomized control trials makes it harder to establish causative associations for various factors.

\section{Conclusions and Future Directions}

There is a wealth of research literature that clearly support a multifaceted role of probiotics in pancreatic cancer prevention by modulating pancreatitis and various other risk factors like diabetes, pancreatic necrosis, inflammation, obesity. The current data are not sufficient to draw conclusions about the effects of probiotics in pancreatic cancer because of the limited number of trials and their heterogeneity. The types of probiotics and treatment strategies employed play an important role in the heterogeneity of clinical outcomes reported in different random controlled trials (RCTs). Though the individual diversity of the intestinal microflora underscores the difficulty of identifying the cascading factors for pancreatic cancer and poses barriers to this field of research.

However, the effectiveness of probiotics are species and strain specific and even a single strain of probiotic may exert its actions via multiple, concomitant pathways in pancreatic cancer prevention. Emerging data suggest synbiotic as a more effective approach than either prebiotics or probiotics alone. More in vivo especially human studies are warranted to further elucidate and confirm the potential role of probiotics, prebiotics and synbiotics in pancreatic cancer prevention. There is no doubt that research investigating the role of probiotics in pancreatic cancer prevention is still in its infancy. In brief, much is still to learn about the role of probiotics in pancreatic cancer, a promising future of its preventive as well as therapeutic approach is certainly on the horizon.

\section{Acknowledgements}

The authors are grateful to Gautam Buddha University for the support and providing necessary facilities for preparing the manuscript.

\section{Conflict of Interest}

All authors declare that they have no conflict of interest.

\section{References}

[1] Whitman, W.B., Coleman, D.C. and Wiebe, W.J. (1998) Prokaryotes: The Unseen Majority. Proceedings of the National Academy of Sciences of the USA, 95, 6578-6583. https://doi.org/10.1073/pnas.95.12.6578

[2] Moran, N.A., McCutcheon, J.P. and Nakabachi, A. (2008) Genomics and Evolution of Heritable Bacterial Symbionts. Annual Review of Genetics, 42, 165-190.

https://doi.org/10.1146/annurev.genet.41.110306.130119

[3] Backhed, F., Ley, R.E., Sonnenburg, J.L., Peterson, D.A. and Gordon, J.I. (2005) Host-Bacterial Mutualism in the Human Intestine. Science, 307, 1915-1920.

https://doi.org/10.1126/science.1104816 
[4] Eckburg, P.B., Bik, E.M., Bernstein, C.N., Purdom, E., Dethlefsen, L. and Sargent, M. (2005) Diversity of the Human Intestinal Microbial Flora. Science, 308, 1635-1638. https://doi.org/10.1126/science.1110591

[5] Grenham, S., Clarke, G., Cryan, J.F. and Dinan, T.G. (2011) Brain-Gut-Microbe Communication in Healthand Disease. Frontiers in Physiology, 2, 94-108.

https://doi.org/10.3389/fphys.2011.00094

[6] Leser, T.D. and Molbak, L. (2009) Better Living through Microbial Action: The Benefits of the Mammalian Gastrointestinal Microbiota on the Host. Environmental Microbiology, 11, 2194-2206. https://doi.org/10.1111/j.1462-2920.2009.01941.x

[7] Costello, E.K., Lauber, C.L., Hamady, M., Fierer, N., Gordon, J.I., et al. (2009) Bacterial Community Variation in Human Body Habitats across Space and Time. Science, 326, 16941697. https://doi.org/10.1126/science.1177486

[8] Tlaskalova-Hogenova, H., Tepankova, R.S., Kozakova, H., Hudcovic, T., Tuckova, L.L., Rossmann, P., Hrncr, T., Kverka, M. and Zákostelska, Z. (2011) The Role of Gut Microbiota (Commensal Bacteria) and the Mucosal Barrier in the Pathogenesis of Inflammatory and Autoimmune Diseases and Cancer: Contribution of Germ-Free and Gnotobiotic Animal Models of Human Disease. Cellular \& Molecular Immunology, 8, 110-120. https://doi.org/10.1038/cmi.2010.67

[9] Vincent, A., Herman, J., Schulick, R., Hruban, R.H. and Goggins, M. (2011) Pancreatic Cancer. Lancet, 378, 607-620. https://doi.org/10.1016/S0140-6736(10)62307-0

[10] Siegel, R., Naishadham, D. and Jemal, A. (2013) Cancer Statistics. CA: A Cancer Journal for Clinicians, 63, 11-30. https://doi.org/10.3322/caac.21166

[11] Mason, P. (2001) Prebiotics and Probiotics. Pharmaceutical Journal, 266, 118-121.

[12] Tannock, G.W. (1997) Probiotic Properties of Lactic-Acid Bacteria: Plenty of Scope for Fundamental R\&D. Trends in Biotechnology, 15, 270-274. https://doi.org/10.1016/S0167-7799(97)01056-1

[13] Colin, H., Francisco, G., Gregor, R., Glenn, R.G. and Daniel, J.M. (2014) Expert Consensus Document: The International Scientific Association for Probiotics and Prebiotics Consensus Statement on the Scope and Appropriate Use of the Term Probiotic. Nature Reviews Gastroenterology \& Hepatology, 11, 506-514. https://doi.org/10.1038/nrgastro.2014.66

[14] Yadav, D. and Lowenfels, A.B. (2013) The Epidemiology of Pancreatitis and Pancreatic Cancer. Gastroenterology, 144, 1252-1261. https://doi.org/10.1053/j.gastro.2013.01.068

[15] Peery, A.F., Dellon, E.S., Lund, J., Crockett, S.D., McGowan, C.E. and Bulsiewicz, W.J. (2012) Burden of Gastro Intestinal Disease in the United States: 2012 Update. Gastroenterology, 143, 1179-1187. https://doi.org/10.1053/j.gastro.2012.08.002

[16] Dervenis, C., Smailis, D. and Hatzitheoklitos, E. (2003) Bacterial Translocation and Its Prevention in Acute Pancreatitis. Journal of Hepato-Biliary-Pancreatic Surgery, 10, 415-418. https://doi.org/10.1007/s00534-002-0727-5

[17] Gianotti, L., Munda, R. and Alexander, J.W. (1992) Pancreatitis-Induced Microbial Translocation: A Study of Mechanisms. Journal of Surgical Research, 4, 87-91.

[18] Medich, D., Lee, T.K., Melhem, M.F., et al. (1993) Pathogenesis of Pancreatic Sepsis. The American Journal of Surgery, 165, 46-52. https://doi.org/10.1016/S0002-9610(05)80403-9

[19] Shrikhande, S.V., Martignoni, M.E., Shrikhande, M., Kappeler, A., Ramesh, H. and Zimmermann, A. (2003) Comparison of Histological Features and Inflammatory Cell Reaction in Alcoholic, Idiopathic and Tropical Chronic Pancreatitis. British Journal of Surgery, 90, 1565-1572. https://doi.org/10.1002/bjs.4353

[20] Yonezawa, S., Higashi, M., Yamada, N. and Goto, M. (2008) Precursor Lesions of Pancrea- 
tic Cancer. Gut and Liver, 2, 137-154. https://doi.org/10.5009/gnl.2008.2.3.137

[21] Siegel, R., Desantis, C., Virgo, K., Stein, K., Mariotto, A. and Smith, T. (2012) Cancer Treatment and Survivorship Statistics. CA: A Cancer Journal for Clinicians, 62, 220-241. https://doi.org/10.3322/caac.21149

[22] Jung, I.H., Jung, D.E., Park, Y.N., Song, S.Y. and Park, S.W. (2011) Aberrant Hedgehog Ligands Induce Progressive Pancreatic Fibrosis by Paracrine Activation of Myofibroblasts and Ductular Cells in Transgenic Zebrafish. PLoS ONE, 6, e27941. https://doi.org/10.1371/journal.pone.0027941

[23] Anderson, K.E., Potter, J.D., Mack, T.M. Schottenfeld, D. and Fraumeni, J.F. (1995) Pancreas Cancer Epidemiology and Prevention Ed. 2. Oxford University Press, New York.

[24] Overvik, E. and Gustafsson, I.A. (1990) Cooked-Food Mutagens: Current Knowledge of Formation and Biological Significance. Mutagenesis, 5, 437-436.

https://doi.org/10.1093/mutage/5.5.437

[25] Ghadirian, P., Thouez, J.P. and Petit Clerc, C. (1991) International Comparisons of Nutrition and Mortality from Pancreatic Cancer. Cancer Detect Prey, 5, 357-362.

[26] Gold, E.B., Gordis, L., Diener, M.D., Seltser, R., Boitnott, J.K., Bynum, T.E. and Hutcheon, D.F. (1985) Diet and Other Risk Factors for Cancer of the Pancreas. Cancer, 55, 460-467. https://doi.org/10.1002/1097-0142(19850115)55:2<460::AID-CNCR2820550229>3.0.CO;2-V

[27] Olsen, G.W., Mandel, J.S, Gibson, R.W., Wattenberg, L.W. and Mschuman, L.M. (1989) A Case-Control Study of Pancreatic Cancer and Cigarettes, Alcohol, Coffee and Diet. American Journal of Public Health, 79, 1016-1019. https://doi.org/10.2105/AJPH.79.8.1016

[28] Kalapothaki, V., Tzonou, A., Hsieh, C.C., Karakatsani, A., Trichopoulou, A., Toupadaki, N. and Trichopoulos, D. (1993) Nutrient Intake and Cancer of the Pancreas:a Case-Control Study in Athens, Greece. Cancer Causes \& Control, 4, 383-389. https://doi.org/10.1007/BF00051342

[29] World Cancer Research Fund/American Institute for Cancer Research. Alcoholic Drinks In: Food, Nutrition, Physical Activity, and Prevention of Cancer: A Global Perspective (2007) Washington DC American Institute for Cancer Research, 157-171.

[30] Whitcomb, D.C. (2011) Genetics and Alcohol: A Lethal Combination in Pancreatic Disease? Alcoholism: Clinical and Experimental Research, 35, 838-842.

https://doi.org/10.1111/j.1530-0277.2010.01409.x

[31] Friedman, G.D. and VandenEeden, S.K. (1993) Risk Factors for Pancreatic Cancer: An Exploratory Study. International Journal of Epidemiology, 22, 30-37. https://doi.org/10.1093/ije/22.1.30

[32] Li, J., Silverman, D.T., Schairer, C., Anne, C.M., Baut, T., Hollenbeck, A.R., Leitzmann, M.F., Schatzkin, A. and Stolzenberg-Solomon, R.Z. (2009) Alcohol Use and Risk of Pancreatic Cancer. American Journal of Epidemiology, 169, 1043-1051. https://doi.org/10.1093/aje/kwp034

[33] Schneider, A. and Singer, M.V. (2005) Alcoholic Pancreatitis. Digital Distribution, 23, 222231.

[34] Kristiansen, L., Gronbaek, M. and Becker, U. (2008) Risk of Pancreatitis According to Alcohol Drinking Habits: A Population-Based Cohort Study. American Journal of Epidemiology, 168, 932-937. https://doi.org/10.1093/aje/kwn222

[35] Bosetti, C., Lucenteforte, E. and Silverman, D.T. (2012) Cigarette Smoking and Pancreatic Cancer: An Analysis from the International Pancreatic Cancer Case-Control Consortium (Panc4). Annals of Oncology, 23, 1880-1888. https://doi.org/10.1093/annonc/mdr541

[36] Zou, L., Zhong, R. and Shen, N. (2014) Non-Linear Dose-Response Relationship between 
Cigarette Smoking and Pancreatic Cancer Risk: Evidence from a Meta-Analysis of 42 Observational Studies. European Journal of Cancer, 50, 193-203.

https://doi.org/10.1016/j.ejca.2013.08.014

[37] Bertuccio, P., La Vecchia, C., Silverman, D.T., et al. (2011) Cigar and Pipe Smoking, Smokeless Tobacco Use and Pancreatic Cancer: An Analysis from the International Pancreatic Cancer Case-Control Consortium (PanC4). Annals of Oncology, 22, 1420-1426. https://doi.org/10.1093/annonc/mdq613

[38] Almoguera, C., Shibata, D., Forrester, K., Martin, J., Arnheim, N. and Perucho, M. (1988) Most Human Carcinomas of the Exocrine Pancreas Contain Mutant c-K-Ras Genes. Cell, 53, 549-554. https://doi.org/10.1016/0092-8674(88)90571-5

[39] Di Magliano, M.P. and Logsdon, C.D. (2013) Roles for KRAS in Pancreatic Tumor Development and Progression. Gastroenterology, 144, 1220-1229. https://doi.org/10.1053/j.gastro.2013.01.071

[40] Sato, Y., Nio, Y. and Song, M. (1997) p53 Protein Expression as Prognostic Factor in Human Pancreatic Cancer. Anticancer Research, 17, 2779-2788.

[41] Permert, J., Adrian, T.E., Jacobsson, P., Jorfelt, L., Fruin, A.B. and Larsson, J. (1993) Is Profound Peripheral Insulin Resistance in Patients with Pancreatic Cancer Caused by a Tumor-Associated Factor? American Journal of Surgery, 165, 61-67. https://doi.org/10.1016/S0002-9610(05)80405-2

[42] Schwarts, S.S., Zeidler, A., Moossa, A.R., Kuku, S.F. and Rubenstein, A.H. (1978) A Prospective Study of Glucose Tolerance, Insulin, C-Peptide, and Glucagon Responses in Patients with Pancreatic Carcinoma. Digital Distribution, 23, 1107-1114. https://doi.org/10.1007/bf01072886

[43] Liu, J., Knezetic, J.A., Strömmer, L., Permert, J., Larsson, J. and Adrian, T.E. (2000) The Intracellular Mechanism of Insulin Resistance in Pancreatic Cancer Patients. The Journal of Clinical Endocrinology \& Metabolism, 85, 1232-1238.

[44] Basso, D., Valerio, A., Seraglia, R., Mazza, S., Piva, M.G., Greco, E., Fogar, P., Gallo, N., Pedrazzoli, S., Tiengo, A. and Plebani, M. (2002) Putative Pancreatic Cancer-Associated Diabetogenic Factor: 2030 MW Peptide. Pancreas, 24, 8-14. https://doi.org/10.1097/00006676-200201000-00002

[45] Wang, F., Herrington, M., Larsson, J. and Permert, J. (2003) The Relationship between Diabetes and Pancreatic Cancer. Molecular Cancer, 2, 1-5. https://doi.org/10.1186/1476-4598-2-4

[46] Monami, M., Colombi, C., Balzi, D., et al. (2011) Metformin and Cancer Occurrence in Insulin-Treated Type 2 Diabetic Patients. Diabetes Care, 34, 129-131. https://doi.org/10.2337/dc10-1287

[47] Elashoff, M., Matveyenko, A.V., Gier, B., et al. (2011) Pancreatitis, Pancreatic, and Thyroid Cancer with Glucagon-Like Peptide-1-Based Therapies. Gastroenterology, 141, 150-156. https://doi.org/10.1053/j.gastro.2011.02.018

[48] Koehler, J.A. and Drucker, D.J. (2006) Activation of Glucagon-Like Peptide-1 Receptor Signaling Does Not Modify the Growth or Apoptosis of Human Pancreatic Cancer Cells. Diabetes, 55, 1369-1379. https://doi.org/10.2337/db05-1145

[49] US Food and Drug Administration. Sitagliptin (Marketed as Januvia and Janumet)-Acute Pancreatitis. 2009. www.fda.gov/Safety/MedWatch/SafetyInformation/SafetyAlertsforHumanMedicalProducts /ucm 183800.htm

[50] US Food and Drug Administration. Byetta (Exenatide) 2007. 
www.fda.gov/Safety/MedWatch/SafetyInformation/SafetyAlertsforHuman,MedicalProduct s/ucm150839.htm

[51] Hemkens, L.G., Grouven, U., Bender, R., et al. (2009) Risk of Malignancies in Patients with Diabetes Treated with Human Insulin or Insulin Analogues: A Cohort Study. Diabetologia, 52, 1732-1744. https://doi.org/10.1007/s00125-009-1418-4

[52] Nothlings, U., Wilkens, L.R., Murphy, S.P., Hankin, J.H., Henderson, B.E. and Kolonel, L.N. (2007) Body Mass Index and Physical Activity as Risk Factors for Pancreatic Cancer: The Multiethnic Cohort Study. Cancer Causes Control, 18, 165-175. https://doi.org/10.1007/s10552-006-0100-0

[53] Hanley, A.J., Johnson, K.C., Villeneuve, P.J. and Mao, Y. (2001) Physical Activity, Anthropometric factors and Risk of Pancreatic Cancer: Results from the Canadian Enhanced Cancer Surveillance System. International Journal of Cancer, 94, 140-147. https://doi.org/10.1002/ijc.1446

[54] Johnson, A.R., Milner, J.J. and Makowski, L. (2012) The Inflammation Highway: Metabolism Accelerates Inflammatory Traffic in Obesity. Immunological Reviews, 249, 218-238. https://doi.org/10.1111/j.1600-065X.2012.01151.x

[55] Stienstra, R., Van Diepen, J.A., Tack, C.J., Zaki, M.H., Vande Veerdonk, F.L. and Perera, D. (2011) Inflammasomeisa Central Player in the Induction of Obesity and Insulin Resistance. Proceedings of the National Academy of Sciences of the USA, 108, 15324-15329. https://doi.org/10.1073/pnas.1100255108

[56] Hruban, R.H., Canto, M.I., Goggins, M., Schulick, R. and Klein, A.P. (2010) Update on Familial Pancreatic Cancer. Advances in Surgery, 44, 293-311. https://doi.org/10.1016/j.yasu.2010.05.011

[57] Murphy, K.M., Brune, K.A. and Griffin, C. (2002) Evaluation of Candidate Genes MAP2K4, MADH4, ACVR1B, and BRCA2 in Familial Pancreatic Cancer: Deleterious BRCA2 Mutations in 17\%. Cancer Research, 62, 3789-3793.

[58] Su, G.H., Hruban, R.H. and Bansal, R.K. (1999) Germline and Somatic Mutations of the STK11/LKB1 Peutz-Jeghers Gene in Pancreatic and Biliary Cancers. American Journal of Pathology, 154, 1835-1840. https://doi.org/10.1016/S0002-9440(10)65440-5

[59] Lynch, H.T., Brand, R.E. and Hogg, D. (2002) Phenotypic Variation in Eight Extended CDKN2A Germline Mutation Familial Atypical Multiple Mole Melanoma-Pancreatic Carcinoma-Prone Families: The Familial Atypical Mole Melanoma-Pancreatic Carcinoma Syndrome. Cancer, 94, 84-96. https://doi.org/10.1002/cncr.10159

[60] Jones, S., Hruban, R.H. and Kamiyama, M. (2009) Exomic Sequencing Identifies PALB2 as a Pancreatic Cancer Susceptibility Gene. Science, 324, 217-227. https://doi.org/10.1126/science.1171202

[61] Amundadottir, L., Kraft, P. and Stolzenberg-Solomon, R.Z. (2009) Genome-Wide Association Study Identifies Variants in the ABO Locus Associated with Susceptibility to Pancreatic Cancer. Nature Genetics, 41, 986-990. https://doi.org/10.1038/ng.429

[62] Eide, D.J. (2006) Zinc Transporters and the Cellular Trafficking of Zinc. Biochimica et Biophysica Acta, 1763, 711-722. https://doi.org/10.1016/j.bbamcr.2006.03.005

[63] Palmiter, R.D. and Huang, L. (2003) Efflux and Compartmentalization of Zinc by Members of the SLC30 Family of Solute Carriers. In: Hediger, M.A., Ed., The ABC of Solute Carriers, Springer-Verlag, New York.

[64] Slucca, M., Harmon, J.S., Oseid, E.A., Bryan, J. and Robertson, R.P. (2010) ATP-Sensitive $\mathrm{K}+$ Channel Mediates the Zinc Switch-Off Signal for Glucagon Response during Glucose Deprivation. Diabetes, 59, 128 -134. https://doi.org/10.2337/db09-1098 
[65] Gyulkhandanyan, A.V., Lu, H., Lee, S.C., Bhattacharjee, A., Wijesekara, N., Fox, J.E., MacDonald, P.E., Chimienti, F., Dai, F.F., et al. (2008) Investigation of Transport Mechanisms and regulation of Intracellular $\mathrm{Zn}^{2+}$ in Pancreatic Alpha-cells. The Journal of Biological Chemistry, 283, 10184-10197. https://doi.org/10.1074/jbc.M707005200

[66] Chimienti, F., Devergnas, S., Favier, A. and Seve, M. (2004) Identification and Cloning of a Beta-Cell Specific Zinc Transporter, ZnT-8, Localized into Insulin Secretory Granules. Diabetes, 53, 2330-2337. https://doi.org/10.2337/diabetes.53.9.2330

[67] Coffman, F.D. and Dunn, M.F. (1988) Insulin-Metal Ion Interactions: The Binding of Divalent Cations to Insulin Hexamers and Tetramers and the Assembly of Insulin Hexamers. Biochemistry, 27, 6179-6187. https://doi.org/10.1021/bi00416a053

[68] Guo, L., Lichten, L.A., Ryu, M.S., Liuzzi, J.P., Wang, F. and Cousins, R.J. (2010) STAT5Glucocorticoid Receptor Interaction and MTF-1 Regulate the Expression of ZnT2 (Slc30a2) in Pancreatic Acinar Cells. Proceedings of the National Academy of Sciences of the USA, 107, 2818-23. https://doi.org/10.1073/pnas.0914941107

[69] Girish, B.N., Rajesh, G., Vaidyanathan, K. and Balakrishnan, V. (2009) Zinc Status in Chronic Pancreatitis and Its Relationship with Exocrine and Endocrine Insufficiency. Journal of Pancreas, 10, 651-656.

[70] Li, M., Zhang, Y., Liu, Z., Bharadwaj, U., Wang, H., Wang, X., Zhang, S., Liuzzi, J.P. and Chang, S.M. (2007) Aberrant Expression of Zinc Transporter ZIP4 (SLC39A4) Significantly Contributes to Human Pancreatic Cancer Pathogenesis and Progression. Proceedings of the National Academy of Sciences of the USA, 104, 18636-18641. https://doi.org/10.1073/pnas.0709307104

[71] Zhang, Y., Bharadwaj, U., Logsdon, C.D., Changyi, C., Yao, Q. and Li, M. (2011) ZIP4 Regulates Pancreatic Cancer Cell Growth by Activating IL-6/STAT3 Pathway via Zinc Finger Transcription factor CREB. Clinical Cancer Research, 16, 1423-1430. https://doi.org/10.1158/1078-0432.CCR-09-2405

[72] Steele, C.W., Jamieson, N.B., Evans, T.R., McKay, C.J., Sansom, O.J. and Morton, J.P. (2013) Exploiting Inflammation for Therapeutic Gain in Pancreatic Cancer. British Journal of Cancer, 108, 997-1003. https://doi.org/10.1038/bjc.2013.24

[73] Scholz, A., Heinze, S., Detjen, K.M., Peters, M., Welzel, M. and Hauff, P. (2003) Activated Signal Transducer and Activator of Transcription 3(STAT3) Supports the Malignant Phenotype of Human Pancreatic Cancer. Gastroenterology, 125, 891-905. https://doi.org/10.1016/S0016-5085(03)01064-3

[74] Kisseleva, T., Bhattacharya, S., Braunstein, J. and Schindler, C.W. (2002) Signaling through the JAK/STAT Pathway, Recent Advances and Future Challenges. Gene, 285, 1-24. https://doi.org/10.1016/S0378-1119(02)00398-0

[75] He, G. and Karin, M. (2011) NF- $\kappa$ B and STAT3-Key Players in Liver Inflammation and Cancer. Cell Research, 21, 159-168. https://doi.org/10.1038/cr.2010.183

[76] Deretic, V. (2012) Autophagy: An Emerging Immunological Paradigm. Journal of Immunology, 189, 15-20. https://doi.org/10.4049/jimmunol.1102108

[77] Ling, J., Kang, Y., Zhao, R., Xia, Q., Lee, D.F. and Chang, Z. (2012) KrasG12D-Induced IKK2/Beta/NF-Kappa B Activation by IL-1 Alpha and p62 Feed forward Loops Is Required for Development of Pancreatic Ductal Adenocarcinoma. Cancer Cell, 21, 105-120. https://doi.org/10.1016/j.ccr.2011.12.006

[78] Green, D.R., Galluzzi, L. and Kroemer, G. (2011) Mitochondria and the Autophagy-Inflammation-Cell Death Axis in Organism Aging. Science, 333, 1109-1112.

https://doi.org/10.1126/science.1201940 
[79] Strowig, T., Henao-Mejia, J., Elinav, E. and Flavell, R. (2012) Inflammasomes in Health and Disease. Nature, 481, 278-286. https://doi.org/10.1038/nature10759

[80] Shi, C.S., Shenderov, K., Huang, N.N., Kabat, J., Abu-Asab, M. and Fitzgerald, K.A. (2012) Activation of Autophagy by Inflammatory Signals Limits IL-1Beta Production by Targeting Ubiquitinated Inflammasomes for Destruction Nat Immunol 13:255263 Controlled Trial. Journal of Clinical Gastroenterology, 45, 442-448.

[81] Hoque, R., Sohail, M., Malik, A., Sarwar, S., Luo, Y. and Shah, A. (2011) TLR9 and the NLRP3 Inflammasome Link Acinar Cell Death with Inflammation in Acute Pancreatitis. Gastroenterology, 141, 358-369. https://doi.org/10.1053/j.gastro.2011.03.041

[82] Aghajan, M., Li, N. and Karin, M. (2012) Obesity, Autophagy and the Pathogenesis of Liver and Pancreatic Cancers. Journal of Gastroenterology and Hepatology, 27, 10-14. https://doi.org/10.1111/j.1440-1746.2011.07008.x

[83] Zhang, Z. and Rigas, B. (2006) NF- $\kappa$ B, Inflammation and Pancreatic Carcinogenesis: NF- $\kappa$ B as a Chemo Prevention Target (Review). International Journal of Oncology, 29, 185-192.

[84] Wang, W., Abbruzzese, J.L., Evans, D.B., Larry, L., Cleary, K.R. and Chiao, P.J. (1999) The Nuclear Factor-Kappa B RelA Transcription Factor Is Constitutively Activated in Human Pancreatic Adenocarcinoma Cells. Clinical Cancer Research, 5, 119-127.

[85] Chandler, N.M., Canete, J.J. and Callery, M.P. (2004) Increased Expression of NF-Kappa B Subunits in Human Pancreatic Cancer Cells. Journal of Surgical Research, 118, 9-14. https://doi.org/10.1016/S0022-4804(03)00354-8

[86] Gukovsky, I. and Gukovskaya, A. (2013) Nuclear Factor-KappaB in Pancreatitis: Jack-ofAll-Trades but Which One Is More Important? Gastroenterology, 144, 26-29. https://doi.org/10.1053/j.gastro.2012.11.016

[87] Whitcomb, D.C. (2004) Inflammation and Cancer V. Chronic Pancreatitis and Pancreatic Cancer. American Journal of Physiology-Gastrointestinal and Liver Physiology, 287, G315G319. https://doi.org/10.1152/ajpgi.00115.2004

[88] Eibl, G., Reber, H.A., Hines, O.J. and Go, V.L. (2004) COX and PPAR Possible Interactions in Pancreatic Cancer. Pancreas, 29, 247-253. https://doi.org/10.1097/00006676-200411000-00002

[89] Sun, W.H., Chen, G.S., Ou, X.L., Yang, Y., Luo, C. and Zhang, Y. (2009) Inhibition of COX2 and Activation of Peroxisome Proliferator Activated Receptor Gamma Synergistically Inhibits Proliferation and Induces Apoptosis of Human Pancreatic Carcinoma Cells. Cancer Letters, 275, 247-255. https://doi.org/10.1016/j.canlet.2008.10.023

[90] Mukherjee, P., Basu, G.D., Tinder, T.L., Subramani, D.B., Bradley, J.M. and Arefayene, M. (2009) Progression of Pancreatic Adenocarcinoma Is Significantly Impeded with a Combination of Vaccine and COX-2 Inhibition. The Journal of Immunology, 182, 216-224. https://doi.org/10.4049/jimmunol.182.1.216

[91] Hill, R., Li, Y., Tran, L.M., Dry, S., Calvopina, J.H. and Garcia, A. (2012) Cell Intrinsic Role of COX-2 in Pancreatic Cancer Development. Molecular Cancer Therapeutics, 11, 2127 2137. https://doi.org/10.1158/1535-7163.MCT-12-0342

[92] Husain, S.Z., Prasad, P., Grant, W.M., Kolodecik, T.R., Nathanson, M.H. and Gorelick, F.S. (2005) The Ryanodine Receptor Mediates Early Zymogen Activation in Pancreatitis. Proceedings of the National Academy of Sciences of the USA, 102, 14386-14391. https://doi.org/10.1073/pnas.0503215102

[93] Wilson, J.S., Apte, M.V., Thomas, M.C., Haber, P.S. and Pirola, R.C. (1992) Effects of Ethanol, Acetaldehyde and Cholesterylesterson Pancreatic Lysosomes. Gut, 33, 1099-1104.

https://doi.org/10.1136/gut.33.8.1099 
[94] Wilson, J.S. and Apte, M.V. (2003) Role of Alcohol Metabolism in Alcoholic Pancreatitis. Pancreas, 27, 311-315. https://doi.org/10.1097/00006676-200311000-00007

[95] Criddle, D.N., Murphy, J., Fistetto, G., Barrow, S., Tepikin, A.V. and Neoptolemos, J.P. (2006) Fatty Acid Ethyl Esters Cause Pancreatic Calcium Toxicity via Inositol Tris Phosphate Receptors and Loss of ATP Synthesis. Gastroenterology, 130, 781-793. https://doi.org/10.1053/j.gastro.2005.12.031

[96] Wakabayashi, K., Nagao, M., Esumi, H. and Sugimura, T. (1992) Food-Derived Mutagens and Carcinogens. Cancer Research, 52, 2092-2098.

[97] Felton, J.S., Knize, M.G., Wu, R.W., Colvin, M.E., Hatch, F.T. and Malfatti, M.A. (2007) Mutagenic Potency of Food-Derived Heterocyclic Amines. Mutation Research, 616, 90-94. https://doi.org/10.1016/j.mrfmmm.2006.11.010

[98] Turesky, R.J. (2007) Formation and Biochemistry of Carcinogenic Heterocyclic Aromatic Amines in Cooked Meats. Toxicology Letters, 168, 219-227.

https://doi.org/10.1016/j.toxlet.2006.10.018

[99] Van Tassell, R.L., Kingston, D.G. and Wilkins, T.D. (1990) Metabolism of Dietary Genotoxins by the Human Colonic Microflora: The Fecapentaenes and Heterocyclic Amines. Mutation Research, 238, 209-221. https://doi.org/10.1016/0165-1110(90)90013-2

[100] Sugimura, T., Wakabayashi, K., Nakagama, H. and Nagao, M. (2004) Heterocyclic Amines: Mutagens/carcinogens Produced during Cooking of Meat and Fish. Cancer Science, 95, 290-299. https://doi.org/10.1111/j.1349-7006.2004.tb03205.x

[101] Kumar, M., Kumar, A., Nagpal, R., Mohania, D., Behare, P., Verma, V., Kumar, P., Poddar, D., Aggarwal, P.K., Henry, C.J., Jain, S. and Yadav, H. (2010) Cancer-Preventing Attributes of Probiotics: An Update. International Journal of Food Sciences and Nutrition, 61, 473496. https://doi.org/10.3109/09637480903455971

[102] Orrhage, K., Sillerström, E., Gustafsson, J.A., Nord, C.E. and Rafter, J. (1994) Binding of Mutagenic Heterocyclic Amines by Intestinal and Lactic Acid Bacteria. Mutation Research, 311, 239-248. https://doi.org/10.1016/0027-5107(94)90182-1

[103] Orrhage, K.M., Annas, A., Nord, C.E., Brittebo, E.B. and Rafter, J.J. (2002) Effects of Lactic Acid Bacteria on the Uptake and Distribution of the Food Mutagen Trp-P-2 in Mice. Scandinavian Journal of Gastroenterology, 37, 215-221. https://doi.org/10.1080/003655202753416902

[104] Sreekumar, O. and Hosono, A. (1998) The Antimutagenic Properties of a Polysaccharide Produced by Bifidobacterium longum and Its Cultured Milk against Some Heterocyclic Amines. Canadian Journal of Microbiology, 44, 1029-1036.

https://doi.org/10.1139/cjm-44-11-1029

[105] Zhang, Y., Wang, L., Zhang, J., Li, Y., He, Q., Li, H., Guo, X., Guo, J. and Zhang, H. (2014) Probiotic Lactobacillus casei Zhang Ameliorates High-Fructose-Induced Impaired Glucose Tolerance in Hyperinsulinemia Rats. European Journal of Nutrition, 53, 221. https://doi.org/10.1007/s00394-013-0519-5

[106] Rhee, C.H. and Park, H.D. (2001) Three Glycoproteins with Antimutagenic Activity Identified in Lactobacillus plantarum KLAB21. Applied and Environmental Microbiology, 67, 3445-3449. https://doi.org/10.1128/AEM.67.8.3445-3449.2001

[107] El-Nezami, H., Kankaanpää, P. Salminen, S. and Ahokas, J. (1998) Physicochemical Alterations Enhance the Ability of Dairy Strains of Lactic Acid Bacteria to Remove Aflatoxin from Contaminated Media. Journal of Food Protection, 61, 466-468.

[108] Niderkorn, V., Boudra, H. and Morgavi, D.P. (2006) Binding of Fusarium mycotoxins by Fermentative Bacteria in Vitro. Journal of Applied Microbiology, 101, 849-856. 
https://doi.org/10.1111/j.1365-2672.2006.02958.x

[109] Ibrahim, F., Halttunen, T., Tahvonen, R. and Salminen, S. (2006) Probiotic Bacteria as Potential Detoxification Tools: Assessing Their Heavy Metal Binding Isotherms. Canadian Journal of Microbiology, 52, 877-885. https://doi.org/10.1139/w06-043

[110] Halttunen, T., Collado, M.C., El-Nezami, H., Meriluoto, J. and Salminen, S. (2008) Combining Strains of Lactic Acid Bacteria May Reduce Their Toxin and Heavy Metal Removal Efficiency from Aqueous Solution. Letters in Applied Microbiology, 46, 160-165. https://doi.org/10.1111/j.1472-765X.2007.02276.x

[111] El-Nezami, H.S., Chrevatidis, A., Auriola, S., Salminen, S. and Mykkänen, H. (2002) Removal of Common Fusarium toxins in Vitro by Strains of Lactobacillus and Propionibacterium. Food Additives \& Contaminants, 19, 680-686. https://doi.org/10.1080/02652030210134236

[112] Lahtinen, S.J., Haskard, C.A., Ouwehand, A.C., Salminen, S.J. and Ahokas, J.T. (2004) Binding of Aflatoxin B1 to Cell Wall Components of Lactobacillus rhamnosus Strain GG. Food Additives \& Contaminants, 21, 158-164. https://doi.org/10.1080/02652030310001639521

[113] Hsieh, F.C., Lee, C.L., Chai, C.Y., Chen, W.T., Lu, Y.C. and Wu, C.S. (2013) Oral Administration of Lactobacillus reuteri GMNL-263 Improves Insulin Resistance and Ameliorates Hepatic Steatosis in High Fructose-Fed Rats. Nutrition \& Metabolism, 10, 35-41. https://doi.org/10.1186/1743-7075-10-35

[114] Sakai, T., Taki, T., Nakamoto, A., Shuto, E., Tsutsumi, R., Toshimitsu, T., Makino, S. and Ikegami, S. (2013) Lactobacillus plantarum OLL2712 Regulates Glucose Metabolism in C57BL/6 Mice Fed a High-Fat Diet. Journal of Nutritional Science and Vitaminology, 59, 144-147. https://doi.org/10.3177/jnsv.59.144

[115] Bejar, W., Hamden, K., Salah, R.B. and Chouayekh, H. (2013) Lactobacillus plantarum TN627 Significantly Reduces Complications of Alloxan-Induced Diabetes in Rats. Anaerobe, 24, 4-11. https://doi.org/10.1016/j.anaerobe.2013.08.006

[116] Park, J.E., Oh, S.H. and Cha, Y.S. (2014) Lactobacillus plantarum LG42 Isolated from Gajami Sikhae Decreases Body and Fat Pad Weights in Diet-Induced Obese Mice. Journal of Applied Microbiology, 116, 145-156. https://doi.org/10.1111/jam.12354

[117] Yadav, H., Jain, S. and Sinha, P.R. (2008) Oral Administration of Dahi Containing Probiotic Lactobacillus acidophilus and Lactobacillus casei Delayed the Progression of Streptozotocin-Induced Diabetes in Rats. Journal of Dairy Research, 75, 189-195. https://doi.org/10.1017/S0022029908003129

[118] Kang, J.H., Yun, S.I., Park, M.H., Park, J.H., Jeong, S.Y. and Park, H.O. (2013) Anti-Obesity effect of Lactobacillus gasseri BNR17 in High-Sucrose Diet-Induced Obese Mice. PLoS ONE, 8, e54617. https://doi.org/10.1371/journal.pone.0054617

[119] Kim, S.W., Park, K.Y., Kim, B., Kim, E. and Hyun, C.K. (2013) Lactobacillus rhamnosus GG Improves Insulin Sensitivity and Reduces Adiposity in High-Fat Diet-Fed Mice through Enhancement of Adiponectin Production. Biochemical and Biophysical Research Communications, 431, 258-263. https://doi.org/10.1016/j.bbrc.2012.12.121

[120] Ejtahed, H.S, Mohtadi-Nia, J., Homayouni-Rad, A., Niafar, M., Asghari-Jafarabadi, M., Mofid, V. and Akbarian-Moghari, A. (2011) Effect of Probiotic Yogurt Containing Lactobacillus acidophilus and Bifidobacterium lactis on Lipid Profile in Individuals with Type 2 Diabetes Mellitus. Journal of Dairy Science, 94, 3288-3294. https://doi.org/10.3168/jds.2010-4128

[121] Ejtahed, H.S., Mohtadi-Nia, J., Homayouni-Rad, A., Niafar, M., Asghari-Jafarabadi, M. and Mofid, V. (2012) Probiotic Yogurt Improves Antioxidant Status in Type 2 Diabetic Patients. 
Nutrition, 28, 539-543. https://doi.org/10.1016/j.nut.2011.08.013

[122] Asemi, Z., Zare, Z., Shakeri, H., Sabihi, S.S. and Esmaillzadeh, A. (2013) Effect of Multispecies Probiotic Supplements on Metabolic Profiles, hs-CRP, and Oxidative Stress in Patients with Type 2 Diabetes. Annals of Nutrition and Metabolism, 63, 1-9. https://doi.org/10.1159/000349922

[123] Kadooka, Y., Sato, M., Imaizumi, K., Ogawa, A., Ikuyama, K., Akai, Y., Okano, M., Kagoshima, M. and Tsuchida, T. (2010) Regulation of Abdominal Adiposity by Probiotics (Lactobacillus gasseri SBT2055) in Adults with Obese Tendencies in a Randomized Controlled Trial. European Journal of Clinical Nutrition, 64, 636-643. https://doi.org/10.1038/ejen.2010.19

[124] Jung, S.P., Lee, K.M., Kang, J.H., Yun, S.I., Park, H.O., Moon, Y. and Kim, J.Y. (2013) Effect of Lactobacillus gasseri BNR17 on Overweight and Obese Adults: A Randomized, DoubleBlind Clinical Trial. Korean Journal of Family Medicine, 34, 80-89. https://doi.org/10.4082/kjfm.2013.34.2.80

[125] Van Minnen, L.P., Timmerman, H.M., Lutgendorff, F., Verheem, A., Harmsen, W., Konstantinov, S.R., Smidt, H., Visser, M.R., Rijkers, G.T., Gooszen, H.G. and Akkermans, L.M. (2007) Modification of Intestinal Flora with Multispecies Probiotics Reduces Bacterial Translocation and Improves Clinical Course in a Rat Model of Acute Pancreatitis. Surgery, 141, 470-480. https://doi.org/10.1016/j.surg.2006.10.007

[126] Muftuoglu, M.A.T., Isikgor, S., Tosun, S. and Saglam, A. (2006) Effects of Probiotics on the Severity of Experimental Acute Pancreatitis. European Journal of Clinical Nutrition, 60, 464-468. https://doi.org/10.1038/sj.ejcn.1602338

[127] Karen, M., Yuksel, O., Akyürek, N., Ofluoglu, E., Çaglar, K., Sahin, T.T., Pasaoglu, H., Memis, L., Akyürek, N. and Bostanci, H. (2010) Probiotic Agent Saccharomyces boulardii Reduces the Incidence of Lung Injury in Acute Necrotizing Pancreatitis Induced Rats. Journal of Surgical Research, 160, 139-144. https://doi.org/10.1016/j.jss.2009.02.008

[128] Oláh, A., Belágyi, T., Pótó, L., Romics, L. and Bengmark, S. (2007) Synbiotic Control of Inflammation and Infection in Severe Acute Pancreatitis: A Prospective, Randomized, Double Blind Study. Hepatogastroenterology, 54, 590-594.

[129] Oláh, A. and Romics, L. (2008) Early Enteral Nutrition in Acute Pancreatitis Benefits and Limitations Langenbecks. Archives of Surgery, 393, 261-269. https://doi.org/10.1007/s00423-008-0291-9

[130] Singhal, B., Pundhir, A. and Maurya, A. (2016) In Vitro Evaluation of Functional Attributes of LABs for the Development of Turmeric Based Probiotic Beverage. American Journal of Research Communication, 9, 141-173.

[131] Akyol, S., Mas, M.R., Comert, B., Ateskan, U., Yasar, M., Aydogan, H., Deveci, S., Akay, C., Mas, N., Yener, N. and Kocar, I.H. (2003) The Effect of Antibiotic and Probiotic Combination Therapy on Secondary Pancreatic Infections and Oxidative Stress Parameters in Experimental Acute Necrotizing Pancreatitis. Pancreas, 26, 363-367.

https://doi.org/10.1097/00006676-200305000-00009

[132] Rau, B., Poch, B., Gansauge, F., Bauer, A., Nussler, A.K., Nevalainen, T., Schoenberg M.H. and Beger, H.G. (2000) Pathophysiologic Role of Oxygen Free Radicals in Acute Pancreatitis: Initiating Event or Mediator of Tissue Damage? Annals of Surgery, 231, 352-360. https://doi.org/10.1097/00000658-200003000-00008

[133] Lutgendorff, F., Trulsson, L.M., Van Minnen L.P., Rijkers, G.T., Timmerman, H.M., Franzén, L.E., Gooszen, H.G., Akkermans, L.M.A. and Söderholm, J.D. (2008) Probiotics Enhance Pancreatic Glutathione Biosynthesis and Reduce Oxidative Stress in Experimental Acute Pancreatitis. American Journal of Physiology-Gastrointestinal and Liver Physiology, 
295, G1111-G1121. https://doi.org/10.1152/ajpgi.00603.2007

[134] Sahin, T., Aydin, S., Yuksel, O., Bostanci, H., Akyurek, N., Memis, L. and Basaran, N. (2007) Effects of the Probiotic Agent Saccharomyces boulardii on the DNA Damage in Acute Necrotizing Pancreatitis Induced Rats. Human \& Experimental Toxicology, 26, 653661. https://doi.org/10.1177/0960327107077596

[135] Gabrilovich, D. and Pisarev, V. (2003) Tumor Escape from Immune Response: Mechanisms and Targets of Activity. Current Drug Targets, 4, 525-536. https://doi.org/10.2174/1389450033490849

[136] Zhong, L., Zhang, X. and Covasa, M. (2014) Emerging Roles of Lactic Acid Bacteria in Protection against Colorectal Cancer. World Journal of Gastroenterology, 20, 7878-7886. https://doi.org/10.3748/wjg.v20.i24.7878

[137] Matsuzaki, T., Yokokura, T. and Mutai, M. (1988) Antitumor Effect of Intrapleural Administration of Lactobacillus casei in Mice. Cancer Immunology Immunotherapy, 26, 209-214. https://doi.org/10.1007/BF00199931

[138] Lee, J.W., Shin, J.G., Kim, E.H., Kang, H.E., Yim, I.B., Kim, J.Y., Joo, H.G. and Woo, H.J. (2004) Immunomodulatory and Antitumor Effects in Vivo by the Cytoplasmic Fraction of Lactobacillus casei and Bifidobacterium longum. Journal of Veterinary Science, 5, 41-48.

[139] Goh, Y.J., Azcárate-Peril, M.A., O’Flaherty, S., Durmaz, E., Valence, F., Jardin, J. and Lortal, S. (2009) Development and Application of a Upp-Based Counter Selective Gene Replacement System for the Study of the S-Layer Protein SlpX of Lactobacillus acidophilus. NCFM Applied and Environmental Microbiology, 75, 3093-3105. https://doi.org/10.1128/AEM.02502-08

[140] Mayer, M.L., Phillips, C.M., Stadnyk, A.W., Halperin, S.A. and Lee, S.F. (2009) Synergistic BM-DC Activation and Immune Induction by the Oral Vaccine Vector Streptococcus gordonii and Exogenous Tumor Necrosis Factor. Molecular Immunology, 46, 1883-1891. https://doi.org/10.1016/j.molimm.2009.02.008

[141] Konstantinov, S.R., Smidt, H., de Vos, W.M., Bruijns, S.C., Singh, S.K., Valence, F., Molle, D., Lortal, S., Altermann, E., Klaenhammer T.R. and Van Kooyk, Y. (2008) S Layer Protein A of Lactobacillus acidophilus NCFM Regulates Immature Dendritic Cell and T Cell Functions. Proceedings of the National Academy of Sciences of the USA, 105, 19474-19479. https://doi.org/10.1073/pnas.0810305105

[142] Mohamadzadeh, M., Duong, T., Sandwick, S.J., Hoover, T. and Klaenhammer, T.R. (2009) Dendritic Cell Targeting of Bacillus anthracis Protective Antigen Expressed by Lactobacillus acidophilus Protects Mice from Lethal Challenge. Proceedings of the National Academy of Sciences of the USA, 106, 4331-4336. https://doi.org/10.1073/pnas.0900029106

[143] Takagi, A., Ikemura, H., Matsuzaki, T., Sato, M., Nomoto, K., Morotomi, M. and Yokokura, T. (2008) Relationship between the in Vitro Response of Dendritic Cells to Lactobacillus and Prevention of Tumorigenesis in the Mouse. Journal of Gastroenterology, 43, 661-669. https://doi.org/10.1007/s00535-008-2212-7

[144] Lee, D.K., Jang, S., Kim, M.J., Kim, J.H., Chung, M.J., Kim, K.J. and Ha, N.J. (2008) Anti-Proliferative Effects of Bifidobacterium adolescentis SPM0212 Extract on Human Colon Cancer Cell Lines. BMC Cancer, 8, 310-315. https://doi.org/10.1186/1471-2407-8-310

[145] Iyer, C., Kosters, A., Sethi, G., Kunnumakkara, A.B., Aggarwal, B.B. and Versalovic, J. (2008) Probiotic Lactobacillus reuteri Promotes TNF-Induced Apoptosis in Human Myeloid Leukemia-Derived Cells by Modulation of NF-KappaB and MAPK Signaling. Cellular Microbiology, 10, 1442-1452. https://doi.org/10.1111/j.1462-5822.2008.01137.x

[146] Frulloni, L., Lunardi, C., Simone, R., et al. (2009) Identification of a Novel Antibody Associated with Autoimmune Pancreatitis. New England Journal of Medicine, 361, 2135-2142. 
https://doi.org/10.1056/NEJMoa0903068

[147] Yu, G., Murphy, G., Michel, A., Weinstein, S.J., Männistö, S., Albanes, D., Pawlita, M. and Stolzenberg-Solomon, R.Z. (2013) Seropositivity to Helicobacter pylori and Risk of Pancreatic Cancer. Cancer Epidemiology, Biomarkers \& Prevention, 22, 2416-2419. https://doi.org/10.1158/1055-9965.EPI-13-0680

[148] Oláh, A., Belágyi, T., Issekutz, A., Gamal, M.E. and Bengmark, S. (2002) Randomized Clinical Trial of Specific Lactobacillus and Fibre Supplement to Early Enteral Nutrition in Patients with Acute Pancreatitis. British Journal of Surgery, 89, 1103-1107. https://doi.org/10.1046/j.1365-2168.2002.02189.x

[149] Besselink, M.G.H., Van Santvoort, H.C., Buskens, E., Boermeester, M.A., Van Goor, H., Timmerman, H.M. and Nieuwenhuijs, V.B. (2008) Probiotic Prophylaxis in Predicted Severe Acute Pancreatitis: A Randomised, Double-Blind, Placebo-Controlled Trial. Lancet, 371, 651-659. https://doi.org/10.1016/S0140-6736(08)60207-X

[150] Oláh, A. and Romics, L. (2014) Enteral Nutrition in Acute Pancreatitis: A Review of the Current Evidence. World Journal of Gastroenterology, 20, 16123-16131. https://doi.org/10.3748/wjg.v20.i43.16123

[151] Bengmark, S. (2008) Is Probiotic Prophylaxis Worthwhile in Patients with Predicted Severe Acute Pancreatitis? Nature Reviews Gastroenterology \& Hepatology, 5, 602-603. https://doi.org/10.1038/ncpgasthep1260

[152] Besselink, M.G.H., Van Santvoort, H.C., Vander Heijden, G.J.M.G., Buskens, E. and Gooszen, H.G. (2009) New Randomized Trial of Probiotics in Pancreatitis Needed? Caution Advised Langenbecks. Archives of Surgery, 394, 191-194. https://doi.org/10.1007/s00423-008-0419-y

[153] Sun, S., Yang, K., He, X., Tian, J., Ma, B. and Jiang, L. (2009) Probiotics in Patients with Severe Acute Pancreatitis: A Meta-Analysis. Langenbeck's Archives of Surgery, 394, 171-177. https://doi.org/10.1007/s00423-008-0379-2

[154] Wen, K., Li, G., Bui, T., Liu, F., Li, Y., Kocher, J., Lin, L., Yang, X. and Yuan, L. (2012) High Dose and Low Dose Lactobacillus acidophilus Exerted Differential Immune Modulating Effects on T Cell Immune Responses Induced by an Oral Human Rotavirus Vaccine in Gnotobiotic Pigs. Vaccine, 30, 1198-1207. https://doi.org/10.1016/j.vaccine.2011.11.107

[155] Sharma, B., Srivastava, S., Singh, N., Sachdev, V., Kapur, S. and Saraya, A. (2011) Role of Probiotics on Gut Permeability and Endotoxemia in Patients with Acute Pancreatitis: A Double-Blind Randomized Controlled Trial. Journal of Clinical Gastroenterology, 45, 442448. https://doi.org/10.1097/MCG.0b013e318201f9e2

[156] Van Baal, M.C., Kohout, P., Besselink, M.G., Van Santvoort, H.C., Benes, Z., Zazula, R., Rijkers, G.T. and Gooszen, H.G. (2012) Probiotic Treatment with Probioflora in Patients with Predicted Severe Acute Pancreatitis without Organ Failure. Pancreatology, 12, 458462. https://doi.org/10.1016/j.pan.2012.08.004

[157] Cui, L.H., Wang, X.H., Peng, L.H., Yu, L. and Yang, Y.S. (2013) The Effects of Early Enteral Nutrition with Addition of Probiotics on the Prognosis of Patients Suffering from Severe Acute Pancreatitis. Chinese Critical Care Medicine, 25, 224-228.

[158] Million M., Maraninchi, M., Henry, M., Armougom, F., Richet, H., Carrieri, P., Valero, R., Raccah, D., Vialettes, B. and Raoult, D. (2012) Obesity-Associated Gut Microbiota Is Enriched in Lactobacillus reuteri and Depleted in Bifidobacterium animalis and Methanobrevibacter smithii. International Journal of Obesity, 36, 817-825.

https://doi.org/10.1038/ijo.2011.153 


\section{Abbreviations}

AP: Acute pancreatitis

BRCA: Breast cancer type 1 susceptibility protein

CP: Chronic pancreatitis

CDKN2A: Cyclin-dependent kinase inhibitor 2A

DAMPs: Damage associated molecular patterns

DM: Diabetes mellitus

(DPP)-4: Dipeptidyl peptidase-4

FAMMM: Familial atypical multiple mole melanoma syndrome

FAEEs: Fatty acid ethyl esters

FDA: Food and Drug Administration

(GLP)-1: Glucagon-like peptide-1

$\mathrm{GLUT}_{4}$ : Glucose transporter 4

HCA: Heterocyclic aromatic amines

IPMN: Intraductal papillary mucinous neoplasms

LAB: Lactic acid bacteria

MCN: Mucinous cystic neoplasms

MOF: Multiple Organ Failure

PDAC: Pancreatic ductal adenocarcinoma

PanINs: Pancreatic intraepithelial neoplasia

PMNL: Polymorphonuclear leukocytes

PKC: Protein kinase C

RCTs: Random controlled trials

RHD: Rel homology domain

ROS: Reactive oxygen species

STK 11: Serine/threonine kinase 11

SAP: Severe acute pancreatitis

Submit or recommend next manuscript to SCIRP and we will provide best service for you:

Accepting pre-submission inquiries through Email, Facebook, LinkedIn, Twitter, etc.

A wide selection of journals (inclusive of 9 subjects, more than 200 journals)

Providing 24-hour high-quality service

User-friendly online submission system

Fair and swift peer-review system

Efficient typesetting and proofreading procedure

Display of the result of downloads and visits, as well as the number of cited articles

Maximum dissemination of your research work

Submit your manuscript at: http://papersubmission.scirp.org/

Or contact abb@scirp.org 